\title{
Benthic solute exchange and carbon mineralization in two shallow subtidal sandy sediments: Effect of advective pore-water exchange
}

\author{
Perran L. M. Cook 1
}

Max Planck Institute for Marine Microbiology, Celsiusstr 1, Bremen, 28359, Germany

\section{Frank Wenzhöfer}

Max Planck Institute for Marine Microbiology, Celsiusstr 1, Bremen, 28359, Germany; Institute of Biology, Marine Biological Laboratory, University of Copenhagen, Strandpromenaden 5, 3000 Helsingør, Denmark

\section{Ronnie N. Glud}

Institute of Biology, Marine Biological Laboratory, University of Copenhagen, Strandpromenaden 5, 3000 Helsingør, Denmark

Felix Janssen

Max Planck Institute for Marine Microbiology, Celsiusstr 1, Bremen, 28359, Germany

\section{Markus Huettel}

Max Planck Institute for Marine Microbiology, Celsiusstr 1, Bremen, 28359, Germany; Department of Oceanography, Florida State University, Tallahassee, Florida 32306-4320

\begin{abstract}
We conducted four field campaigns to evaluate benthic $\mathrm{O}_{2}$ consumption and the effect of advective pore-water flow in nearshore permeable sediments in the North Sea and Baltic Sea. Advective pore-water transport had a marked effect on the benthic exchange of $\mathrm{O}_{2}$ and $\mathrm{TCO}_{2}$ in benthic chamber incubations, with the rates of exchange increasing by a factor of up to 2.5 when imposing flushing rates of $100-300 \mathrm{~L} \mathrm{~m}^{-2} \mathrm{~d}^{-1}$, compared to settings with diffusive exchange only. Estimates of in situ exchange rates using oxygen penetration and volumetric $\mathrm{O}_{2}$ consumption and $\mathrm{TCO}_{2}$ production rates were within the range measured in the chambers. The contribution of advection to solute exchange was highly variable and dependent on sediment topography. Advective processes also had a pronounced influence on the in situ distribution of $\mathrm{O}_{2}$ within the sediment, with characteristic twodimensional patterns of $\mathrm{O}_{2}$ distribution across ripples, and also deep subsurface $\mathrm{O}_{2}$ pools, being observed. Mineralization pathways were predominantly aerobic when benthic mineralization rates were low and advective pore-water flow high as a result of well-developed sediment topography. By contrast, mineralization proceeded predominantly through sulfate reduction when benthic mineralization rates were high and advective pore-water flow low as a result of poorly developed topography. Previous studies of benthic mineralization in shallow sandy sediments have generally ignored these dynamics and, hence, have overlooked crucial aspects of permeable sediment function in coastal ecosystems.
\end{abstract}

${ }^{1}$ To whom correspondence should be addressed. Present address: School of Chemistry, Monash University, Clayton, Victoria, 3800, Australia (perran.cook@sci.monash.edu.au).

\section{Acknowledgments}

We thank Anni Glud, Anders Tengberg, Susanne Menger, Stefanie Hedtkamp, Martina Löbl, and Helmy Cook for assistance in the field and the laboratory. Aanderaa Instruments kindly lent us the RCM 9. Justus Van Beusekom provided access to the 'Wattenmeer station' and Krzysztof Skóra to the 'Hel Marine Station,' and we thank the staff of the two stations for their support of the project. We thank Hans Røy for stimulating discussions on aspects of this work, and we thank Oleksiy Galaktionov and Filip Meysman for their assistance with setting up the reactive transport models. We thank Antje Boetius and Bo Barker Jørgensen for supporting this work. We thank Bo Thamdrup and two anonymous reviewers, whose thoughtful comments helped improve this manuscript.

This work was funded by the European Union as part of the project COSA (Coastal Sands as Biocatalytical Filters), contract EVK3-CT-2002-00076, and the Max Planck Society.
Sandy sediments comprise $\sim 70 \%$ of the continental shelf area (Emery 1968), and while biogeochemical studies of this sediment type do exist, particularly in nearshore sediments (e.g., Hargrave and Phillips 1981; Kristensen 1993; Ferguson et al. 2003), they have generally been overlooked in comparison to fine-grained cohesive (muddy) sediments (Boudreau et al. 2001). One of the crucial differences between cohesive and permeable sediments is that transport of solutes can occur by advective pore-water flow generated by the interaction of bottom currents with sediment topography, density gradients, and wave action (Huettel and Webster 2001). This pore-water advection complicates the conceptualization and measurements of benthic processes compared to cohesive sediments.

Rates of benthic carbon mineralization are often assessed by measuring the consumption of $\mathrm{O}_{2}$ or the production of $\mathrm{TCO}_{2}$ by the sediment. $\mathrm{O}_{2}$ consumption within sediments is considered to occur through two major pathways - direct heterotrophic consumption and the 
reoxidation of reduced chemical species such as $\mathrm{Fe}^{2+}$ and $\mathrm{S}^{2-}$, produced by anaerobic processes deeper within the sediment. The former process represents mineralization as it occurs, the latter is temporally decoupled from the anaerobic mineralization. Assuming a situation close to steady state, $\mathrm{O}_{2}$ consumption will provide a good integrated measure of sediment mineralization. In reality, changes in organic matter supply and transport rates (e.g., bioirrigation) over an annual cycle may mean that periods of net reduction $\left(\mathrm{O}_{2}\right.$ flux $<$ mineralization $)$ and net oxidation $\left(\mathrm{O}_{2}\right.$ flux $>$ mineralization) occur (e.g., Therkildsen and Lomstein 1993; Ferguson et al. 2003). In addition to the aforementioned natural cycles of net solute reduction and oxidation, sediment sampling and incubation have the potential to disrupt the in situ solute transport regimes and, hence, the rate of sediment $\mathrm{O}_{2}$ consumption. $\mathrm{TCO}_{2}$ fluxes provide a more direct measure of organic matter mineralization; however, their interpretation is complicated by the precipitation and dissolution of carbonates within the sediment. Ideally both $\mathrm{O}_{2}$ and $\mathrm{TCO}_{2}$ should be measured concurrently and their ratios used to gain an insight into processes occurring within the sediment (e.g., Hargrave and Phillips 1981; Anderson et al. 1986).

In cohesive sediments, the net benthic fluxes of solutes are generally considered to reflect the rates at which these processes are occurring within the sediment, assuming steady state. Hence, the rates of processes in cohesive sediments can be measured by employing chambers, which are placed over the sediment surface. It is generally assumed that this approach does not greatly affect solute exchanges, provided that a reasonable diffusive boundary-layer thickness is maintained, that the length of the incubation does not lead to depletion or inhibiting build-up of reactants, and that the activity of macrofauna remains unaffected (Glud et al. 1995, 2003).

In permeable sediments, where pore-water advection may be a major transport process in the upper sediment layers, the assumption of benthic exchange reflecting a steady-state situation may not be valid. This is because the rate of pore-water advection is partially dependent on sediment topography and currents, both of which change on timescales of minutes to hours to days in an unpredictable manner (Precht and Huettel 2004). Hence, after a period of relative calm there may be a build-up of solutes in the pore water, solutes that are washed out during a more turbulent period in a non-steady-state manner. Moreover, chamber emplacement and sediment coring are both likely to reduce advective solute transport because they exclude in situ bottom currents, and it has been estimated that the time needed for solute distribution and fluxes to reequilibrate to the new transport regime may number in the days or weeks (Jahnke et al. 2005; Cook et al. 2006). Thus, in order to measure benthic exchange in permeable sediments, some sort of "representative" pore-water flushing rate needs to be maintained during benthic chamber incubations. Choosing a representative sediment flushing rate is also greatly confounded by the fact that there are very few in situ estimates or measurements of representative flushing rates (Precht and Huettel 2003, 2004; Reimers et al. 2004; Cook et al. 2006).
The development of chambers generating known pressure gradients over the sediment surface (and, hence, porewater advection within the chamber; Huettel and Gust 1992; Janssen et al. 2005a) has allowed benthic exchange measurements to be conducted under controlled conditions in the presence and absence of advection (Janssen et al. 2005b). These experiments showed that the in situ benthic uptake of $\mathrm{O}_{2}$ may be enhanced under conditions of advective flow, as compared to purely diffusive conditions. Attempts to relate the chamber-determined $\mathrm{O}_{2}$ consumption to in situ biogeochemical activity have been limited to date, primarily as a result of technological shortcomings. In a recent study, De Beer et al. (2005) combined measurements of in situ $\mathrm{O}_{2}$ penetration with measured rates of volumetric $\mathrm{O}_{2}$ consumption to obtain another estimate of in situ sediment $\mathrm{O}_{2}$ consumption, and they found that these rates were about twice as high as those measured in in situ chamber incubations conducted at moderate sediment flushing rates $\left(64 \mathrm{~L} \mathrm{~m}^{-2} \mathrm{~d}^{-1}\right)$. The results of this study highlight the difficulty in choosing a representative in situ flushing rate, indicating that benthic exchange measurements in chamber incubations should be conducted at a range of sediment flushing rates, which can then be related to estimates of in situ flushing or solute exchange rates, such as $\mathrm{O}_{2}$. The suggestion that pore-water advection has a strong influence on solute exchange rates also calls into question the representativeness of benthic $\mathrm{O}_{2}$ and $\mathrm{TCO}_{2}$ exchange measurements in sandy sediments, which to date have included no consideration of advective exchange processes (e.g., Hargrave and Phillips 1981; Hopkinson et al. 1999; Kristensen 1993).

To date, there have been few integrated in situ studies employing a range of techniques to measure benthic solute distribution within the sediment, exchange with the water column, and interactions with advective processes (De Beer et al. 2005; Werner et al. 2006). Such studies are needed in order to fundamentally assess (1) the extent to which porewater advection affects solute distributions in situ, (2) the relationship between benthic solute fluxes in sandy sediments, and (3) the rates of processes taking place within these sediments. For this reason, the aims of this study were to investigate the effect of advective processes on the exchange of $\mathrm{O}_{2}$ and $\mathrm{TCO}_{2}$ and to gain a mechanistic understanding of these interactions, and an estimate of in situ exchange rates, using experimentally measured volumetric $\mathrm{O}_{2}$ consumption, $\mathrm{TCO}_{2}$ production, and sulfate reduction rates combined with measured in situ $\mathrm{O}_{2}$ distributions. The implications of the findings are discussed with reference to existing measurements of benthic $\mathrm{O}_{2}$ consumption and $\mathrm{TCO}_{2}$ production in sandy sediments.

\section{Materials and methods}

Study site - The two field sites chosen for this study were located on the Island of Sylt in the German Waddensee (hereafter referred to as Sylt) and the Hel Peninsula on the Baltic coast in Poland (hereafter referred to as Hel). Two 3week-long field campaigns were conducted at each site (Sylt: 28 April-16 May 2003 and 12-30 July 2004, hereafter 
referred to as Sylt spring and summer campaigns, respectively; Hel: 11 August-29 August 2003 and 19 April-07 May 2004, hereafter referred to as Hel summer and spring campaigns). The shallow sublittoral study site at Sylt is situated $\sim 600 \mathrm{~m}$ south of List Harbor and has an average water depth of $\sim 0.5 \mathrm{~m}$ at low tide. The site is protected from the prevailing westerly winds by the island. The study site at Hel was located directly off the beach at the township of Hel. The water depth at the study site was $\sim 1.5 \mathrm{~m}$, the tidal influence is minimal, and small changes in water depth at the site are controlled by wind-driven seiches. During each field campaign, a RCM 9 recording current meter (Aanderraa) was deployed, which recorded average temperature, salinity, and current speed as well as dissolved oxygen every $5 \mathrm{~min}$ for periods of between $2 \mathrm{~d}$ and $7 \mathrm{~d}$ (Fig. 1a,b). During the Sylt summer campaign and the Hel spring campaign, an ADV (Acoustic Doppler Velocimeter) was simultaneously deployed to measure current velocities $0.1-0.2 \mathrm{~m}$ above the sediment at high temporal resolution $(25 \mathrm{~Hz})$ in order to discriminate between steady and oscillating/turbulent current components (Fig. 2a-c). Tides with an amplitude of 1-2 m induce unidirectional currents that may reach $\sim 0.8 \mathrm{~m} \mathrm{~s}^{-1}$ (Fig. 1a) and follow the direction of the shoreline (northeast and southwest during ebb and flood tides, respectively). The wave-driven oscillating component of the current was negligible at this site in comparison to unidirectional current flow (Fig. 2a).

In contrast to Sylt, the steady shore-parallel (northwestsoutheast) component of the currents is much slower at $\mathrm{Hel}$ (Fig. 1c,d). ADV measurements obtained during the spring campaign showed oscillating, periodic, wave-driven currents represented the main flow component (Fig. 2b). Currents were typically directed perpendicular to the shoreline (northeast-southwest) and had an average ( \pm standard deviation $[\mathrm{SD}]$ ) root mean square (RMS) current speed of $3.16 \pm 1.95 \mathrm{~cm} \mathrm{~s}^{-1}(n=143)$, as compared to the average steady flow of $1.84 \pm$ $1.05 \mathrm{~cm} \mathrm{~s}^{-1}$ in the same recordings. The salinity at $\mathrm{Hel}$ is low $(\sim 7)$, reflecting the brackish nature of the Baltic Sea as well as the local freshwater inflow from the Vistula River into the Gulf of Gdansk. By contrast, the relatively high salinity at Sylt $(\sim 30)$ reflects a slight coastal decrease from the fully marine North Sea salinity.

A summary of key water column and sediment parameters measured during the field campaigns is presented in Table 1. Although water column nutrients were generally low during the field campaigns, they were markedly higher at Sylt, particularly during late autumn to early spring (S. Hedtamp and L. Kotwicki unpubl. data, www.iopan.gda.pl/projects/cosa). The sediment chlorophyll $a(\mathrm{Chl} a)$ content was also much higher at Sylt (13-21 $\mu \mathrm{g}$ $\mathrm{g}^{-1}$ sediment [sed]) than at Hel (3-3.9 $\mu \mathrm{g} \mathrm{g}^{-1}$ sed), as were rates of benthic primary production (Wenzhöfer unpubl. data) and the sediment organic carbon (C) content. The $\mathrm{C}$ : nitrogen ratio of the sediment was 7-8 at Sylt and could not be determined at $\mathrm{Hel}$ as a result of the low organic matter content. The organic matter at both sites is most likely derived from algal material, as indicated by the $\delta^{13} \mathrm{C}$ signature of the sediments $(-16 \%$ to $-21 \%$; Heip et al.
1995). During our field campaigns, sediment permeability was slightly higher at Hel $\left(2.9-4.6 \times 10^{-11} \mathrm{~m}^{2}\right)$ than at Sylt $\left(2-2.2 \times 10^{-11} \mathrm{~m}^{2}\right)$.

Sediment topography - Sediment topography was measured using an autonomous laser scanning instrument, following the method described by Røy et al. (2005). A total of 46 sediment surface topography scans were obtained in April/May 2004 at Sylt, and a total of 17 scans were obtained in July 2004 at Hel. Images of an approximately $250 \mathrm{~mm}$-long and $<1$-mm-wide straight line that was projected vertically onto the seafloor $\left(6.7 \times 10^{-7} \mathrm{~m}\right.$ diode laser with line optics) were taken from an angle of $45^{\circ}$ using a digital camera (Nikon CoolPix 990 in an underwater housing). Scans of 700-mm length were derived from 141 images that were obtained while a linear drive shifted the camera and laser in 5-mm increments horizontally over the sediment surface. The scanning direction of the instrument was aligned to the direction of the main flow (i.e., to the oscillating currents at $\mathrm{Hel}$ and the tidal currents at Sylt). Pixel coordinates of the laser line in the respective images were transformed into absolute coordinates (i.e., seafloor elevations in the plane of the laser sheet) based on a calibration obtained from images of a calibration grid. The surface elevation profiles of the 141 images were assembled to a three-dimensional (3D) surface topography with a grid size of $5 \mathrm{~mm} \times 5 \mathrm{~mm}$ in the horizontal direction. Outliers in the sediment surface detection, originating from the presence of motile macrofauna (crabs, fish) at the sediment surface or from poor visibility of the laser line as a result of background daylight, were identified by simple and robust filters (pixel brightness, maximum/minimum height threshold, maximum deviation from neighboring heights) and were replaced by the average height of the neighboring measurements. In order to determine typical dimensions of the ripples at $\mathrm{Hel}$, sinusoidal curves were fitted to profiles that were extracted from the $3 \mathrm{D}$ surface topographies along the center line.

Chamber incubations - The fluxes of $\mathrm{O}_{2}$ and $\mathrm{TCO}_{2}$ and sediment flushing rates were measured using benthic chambers, for which known relationships between stirring speed, as well as stirrer disk-sediment distance and pressure gradient within the chamber, have been established (Janssen et al. 2005a). Incubations were performed ex situ (Sylt: spring 2003; Hel: summer 2003) as well as in situ (Hel: spring 2004; Sylt: summer 2004). For the ex situ incubations, 10 intact cores of sand were collected manually using the chambers as core liners. Cores were immediately returned to the laboratory, where they were kept submerged in a trough filled with water from the study site at in situ temperature and salinity for at least $24 \mathrm{~h}$ before incubations commenced. During this acclimatization period, all chambers had their lids propped open over the cores, allowing free exchange of water between the core and the bath while the cores were stirred. The day before incubations commenced, the speed of the stirrer motors was adjusted (20-80 rpm) to give a pressure gradient ranging from $0 \mathrm{~Pa} \mathrm{~cm}^{-1}$ (diffusive) up to $\sim 1 \mathrm{~Pa} \mathrm{~cm}^{-1}$. The "diffusive" setting was achieved by reversing the 


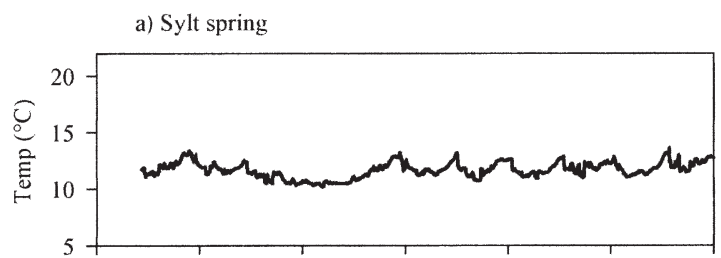

b) Sylt summer
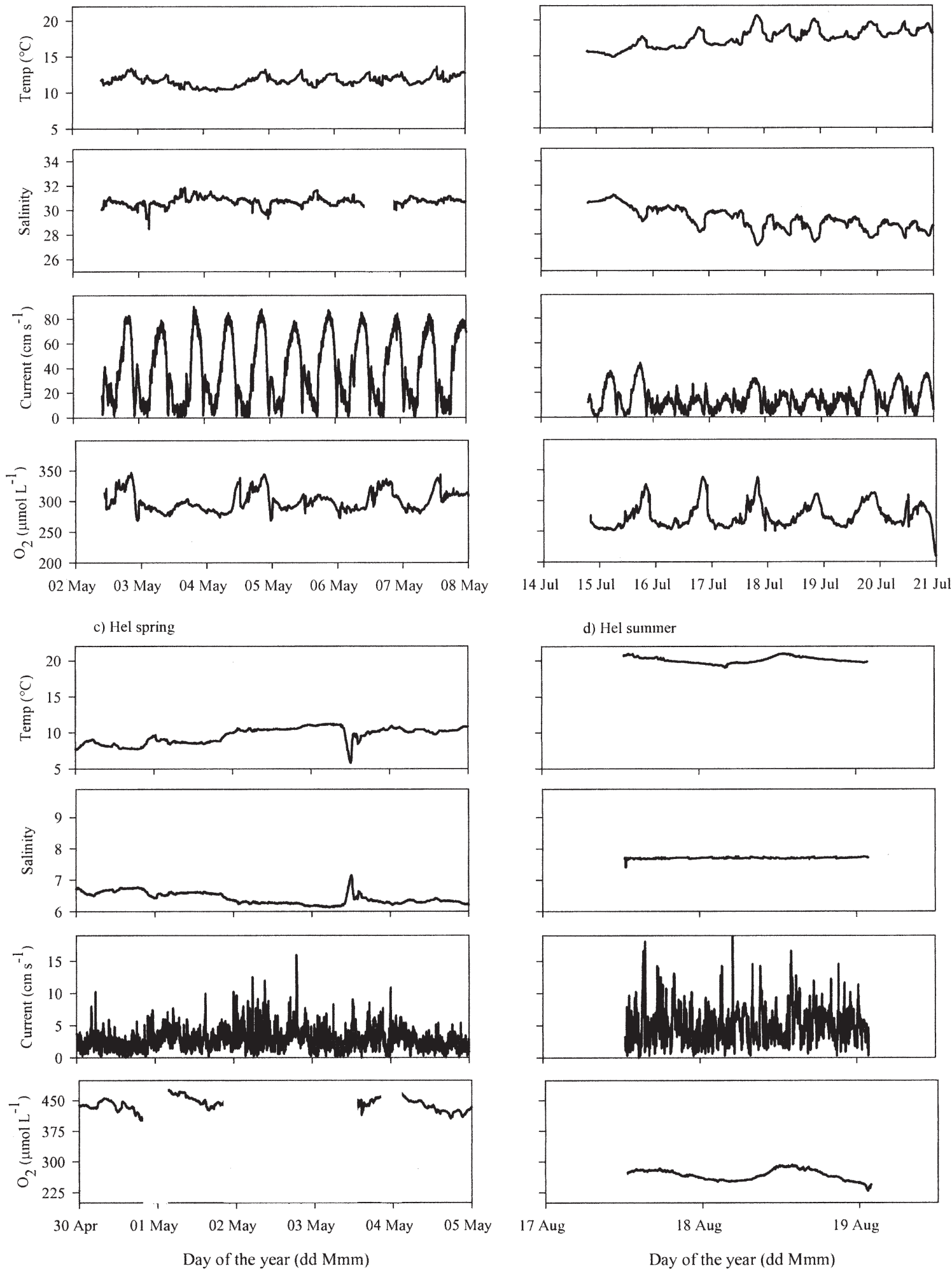

Fig. 1. Time series of in situ temperature, salinity, current speed, and $\mathrm{O}_{2}$ concentrations measured using a $\mathrm{RCM} 9$ data logging device during the field campaigns at (a) Sylt in spring, (b) Sylt in summer, (c) Hel in spring, and (d) Hel in summer. 

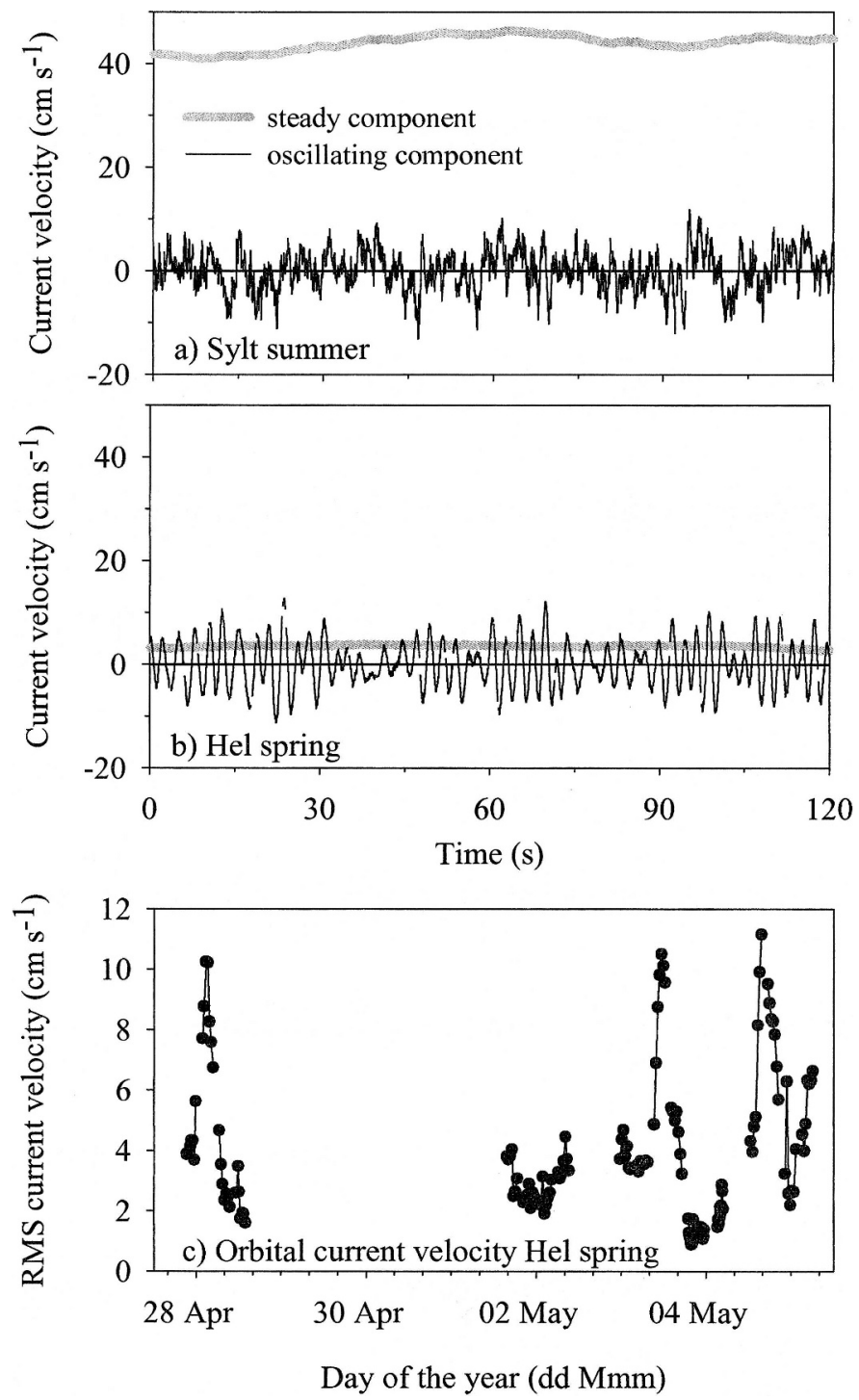

Fig. 2. One hundred twenty-second excerpts of horizontal current speed measurements obtained at a sampling frequency of $25 \mathrm{~Hz}$ during the field campaigns at (a) Sylt (15 July 2004, 06:00 h at ebb tide) and (b) Hel (01 May 2004, 15:30 h). Measuring height was $0.1-0.2 \mathrm{~m}$ above the sediment. The gray lines represent the moving average (averaging period $30 \mathrm{~s}$ ) in the direction of the principal steady flow component $\left(60^{\circ}\right.$ at Sylt, $341^{\circ}$ at Hel). The black lines show the $25-\mathrm{Hz}$ recordings in the direction of the principal oscillating/turbulent current component (i.e., the direction at which individual measurements deviate the most from the mean current; $57^{\circ}$ at Sylt, $42^{\circ}$ at Hel). In this case the 30 -s moving average current speed in the same direction is subtracted. (c) Shows the RMS velocity of the orbital current velocity over time at Hel in spring 2004.

stirring $(20 \mathrm{rpm})$ direction at $15-\mathrm{s}$ time intervals, which caused a mixing of the chamber water without creating a significant pressure gradient. For the incubation, chamber lids were closed, while stirring continued at the prescribed rpm rate. For the in situ incubations, 10 chambers were placed in the field in the late afternoon. At dusk, the lids were placed on the chambers and the stirring speed of the motors was adjusted to the same range of stirring speeds used for the lab incubations. At an additional stirrer speed of $160 \mathrm{rpm}$, which was only applied in situ, the relationship between stirrer speed and pressure gradient was beyond the range defined by Janssen et al. $(2005 a)$, and sediment resuspension also occurred. Therefore, ascribing a pressure gradient to this setting was deemed inappropriate, and these data points are referred to as "resuspended." For both in situ and ex situ incubations, the chambers were sampled periodically for $\mathrm{O}_{2}$, nutrients, and $\mathrm{TCO}_{2}$. Samples for $\mathrm{O}_{2}$ were fixed immediately with Winkler reagents (Grasshoff 1983), $\mathrm{TCO}_{2}$ samples were preserved with $\mathrm{HgCl}_{2}$ (0.01\% final concentration), and nutrient samples were filtered immediately through $0.2-\mu \mathrm{m}$ filters and frozen. At Hel, during spring 2004, a large algal bloom was present during the chamber incubations (reflected in the high $\mathrm{O}_{2}$ concentrations in the water column; Fig. 1c), and the rates of sediment $\mathrm{O}_{2}$ consumption and $\mathrm{TCO}_{2}$ production were thus corrected for water column respiration, measured using in situ bottle incubations. Sediment flushing rates were measured in the chambers by following the gradual decrease in the concentration of $\mathrm{NaBr}$ that was previously added to the overlying water to a final concentration of $\sim 5-10 \mathrm{mmol}$ $\mathrm{L}^{-1}$. Rates of solute exchange between the sediment and the water column were calculated based on linear regression analysis of the concentration change of the solute within the chamber versus time ( $n=3-4$ data points). The flux was only considered significant if the magnitude of the slope was greater than the standard error of the regression.

Modeled sediment flushing rates-Flushing rates of the chambers induced by the scaled pressure fields were calculated using a model created using the finite elements modeling software package Comsol Multiphysics (www.comsol.com). A detailed description of this 'flow model' can be found in Cook et al. (2006). Briefly, the model domain represents the sediment within an incubation core, as described in Janssen et al. (2005a), that had a core radius, $r_{c}$, of $95 \mathrm{~mm}$ and a sediment depth of $200 \mathrm{~mm}$. The model assumes a flat sediment surface, no heterogeneity in sediment parameters like porosity and permeability, and a perfect radial-symmetric stirring pattern in the overlying water. Under such "idealized" conditions, pore-water flow and concentration patterns will be radially symmetric. This way, the physically 3D model domain can be described mathematically by a two-dimensional model, which incorporates only two spatial variables (i.e., the depth, $z$, and the distance, $r$, from the central symmetry axis). A triangular unstructured mesh was used to discretize the model domain, with an element size of $\sim 100 \mu \mathrm{m}$ at the upper boundary (sediment surface), increasing to $10 \mathrm{~mm}$ at the lower boundary of the core.

The pressure distribution in the pore water was calculated using the 'Laplace' equation, thus:

$$
\nabla^{2} p=0
$$

where $p$ is pressure and $\nabla$ the gradient operator using the following boundary conditions. Along the bottom and lateral walls, we implemented a no-flux condition. At the 
Table 1. Summary of key parameters at the field campaigns for which data are presented. Chlorophyll $a($ Chl $a)$, \% carbon (\%C), carbon : nitrogen $(\mathrm{C}: \mathrm{N})$, and $\delta^{13} \mathrm{C}$ values refer to the top $1 \mathrm{~cm}$ of sediment; permeability and porosity refer to the top $5 \mathrm{~cm}$ of sediment.

\begin{tabular}{|c|c|c|c|c|}
\hline & \multicolumn{2}{|c|}{ Sylt* } & \multicolumn{2}{|c|}{ Hel } \\
\hline & Spring 2003 & Summer 2004 & Summer 2003 & Spring 2004 \\
\hline \multicolumn{5}{|l|}{ Sediment } \\
\hline Chl $a\left(\mu \mathrm{g} \mathrm{g}^{-1}\right)$ & 21 & 13 & 3.9 & 3 \\
\hline$\% \mathrm{C}$ & 0.2 & 0.2 & 0.05 & 0.05 \\
\hline $\mathrm{C}: \mathrm{N}$ ratio & 7.6 & 7.9 & - & - \\
\hline$\delta^{13} \mathrm{C}(\%)$ & -18 & -17 & -16 & -21 \\
\hline Permeability $\left(\times 10^{-11} \mathrm{~m}^{2}\right)$ & $2.2 \pm 0.2$ & $2.0 \pm 0.2$ & $4.6 \pm 0.2$ & $2.9 \pm 0.2$ \\
\hline Porosity & 0.45 & 0.39 & - & 0.36 \\
\hline \multicolumn{5}{|c|}{ 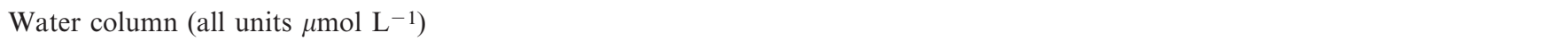 } \\
\hline$\left[\mathrm{NO}_{3}^{-}\right]$ & 7.7 & 0.07 & 1.72 & 0.22 \\
\hline$\left[\mathrm{NH}_{4}^{+}\right]$ & 0.47 & $<0.5$ & 1.45 & 0.75 \\
\hline$\left[\mathrm{HPO}_{4}^{2-}\right]$ & 0.07 & 0.28 & 0.34 & 0.22 \\
\hline$\left[\mathrm{Si}(\mathrm{OH})_{4}\right]$ & 0.47 & 1.29 & 13 & 5.12 \\
\hline
\end{tabular}

* Sylt, Island of Sylt; Hel, Hel Peninsula.

sediment surface, we adopted the pressure relation

$$
p(r, 0)=2 p_{0}\left(\frac{r^{2}}{r_{c}^{2}}-\frac{r^{4}}{2 r_{c}^{4}}\right)
$$

where $p_{0}$ is the pressure at the outer edge of the chamber. This relationship provided a good approximation for the pressure sensor data of Janssen et al. (2005a), measured at $40 \mathrm{rpm}\left(p_{0}=\sim 2\right)$. The magnitude of $p_{0}$ was modified for various stirring speeds by scaling it according to the relationship between pressure and stirring speed given by Janssen et al. (2005a). Together, Eqs. 1 and 2 produce the pressure distribution in the pore water, from which one can subsequently calculate the associated velocity vector field using Darcy's Law (see Meysman et al. [2005] for details on this procedure). For each flow simulation, we calculated the associated sediment flushing rates $\left(\mathrm{L} \mathrm{m}^{-2} \mathrm{~d}^{-1}\right)$ by integrating the vertical component of the simulated porewater velocity along the sediment surface divided by the core area. Flushing rates were initially modeled for a range of pressured fields with a sediment permeability of $2 \times$ $10^{-11} \mathrm{~m}^{2}$ and a water viscosity of $1.1 \times 10^{-3} \mathrm{~kg} \mathrm{~m}^{-2} \mathrm{~s}^{-1}$. A linear relationship was found between the average pressure gradient across the chamber $\left(P_{a v}\right)$ and flushing rate $(F)\left(F=78 P_{a v}-0.32, r^{2}=0.999\right)$, and thus, the flushing rates in the chambers in the field were calculated from $P_{a v}$ and then scaled linearly to water viscosity and measured sediment permeability.

Microprofiles-A profiling lander equipped with four Clark-type $\mathrm{O}_{2}$ microelectrodes (Revsbech 1989; Glud et al. 2000), three $\mathrm{H}_{2} \mathrm{~S}$ microelectrodes (Jeroschewski et al. 1996), and one resistivity sensor was used to repeatedly measure one-dimensional microprofiles across the sediment-water interface and within the sediment (Gundersen and Jørgensen 1990; Wenzhöfer et al. 2000). To make the sensors stable enough to penetrate the sand present at the field sites, both types of microsensors were prepared with outer tip diameters of $\sim 300 \mu \mathrm{m}$, while the actual sensing surface was $5 \mu \mathrm{m}$ (De Beer et al. 2005). The $\mathrm{O}_{2}$ microelectrodes had a linear response toward the $\mathrm{O}_{2}$ concentration in seawater and were calibrated in situ using the constant readings in the bottom water (with a known $\mathrm{O}_{2}$ concentration determined by Winkler titration) and the anoxic parts of the sediment (the zero-point of the electrodes was also crosschecked in the laboratory at in situ temperature). The $\mathrm{H}_{2} \mathrm{~S}$ microelectrodes were calibrated in a degassed phosphate buffer in which the $\mathrm{H}_{2} \mathrm{~S}$ concentration was increased stepwise by adding aliquots of a $100-\mathrm{mmol} \mathrm{L}^{-1} \mathrm{Na}_{2} \mathrm{~S}$ solution (Wenzhöfer et al. 2000). After placing the instrument on the sediment surface, the central sensor array was lowered in steps of $1,000-2,500 \mu \mathrm{m}$ over a depth of 5$10 \mathrm{~cm}$, and all sensor readings were logged at each depth horizon. Microprofiles were typically measured every 20 $30 \mathrm{~min}$ along the same vertical axis for a total period of 12 $24 \mathrm{~h}$. For most of the $\mathrm{O}_{2}$ microprofiles obtained, the relative position of the sediment surface was identified by a distinct break in the concentration gradient. Additionally, the distinct change in signal from the resistivity sensor, when penetrating through the sediment-water interface, in combination with still pictures and video records allowed the alignment of the recorded microprofiles to the actual sediment surface present at each profiling routine. The $\mathrm{O}_{2}$ penetration depth was inferred directly from the microprofiles.

Planar optode-For two-dimensional $\mathrm{O}_{2}$ distribution measurements at each of the field sites, an autonomous, in situ planar optode module was deployed (Glud et al. 2005). The planar optode was based on a rutheniumfluorophore embedded in plasticized polyvinyl chloride sandwiched between a transparent support foil and an optical insulation of black silicon (Glud et al. 1996). The planar optode was placed on the front of an inverted periscope, and images of the $\mathrm{O}_{2}$-quenched fluorescence emitted by the immobilized fluorochrome were recorded using a digital CCD camera (SensiCam, PCO Computer Optics) placed in a central housing (for more details, see Glud et al. 2001, 2005; Wenzhöfer and Glud 2004). For calibration purposes, initial images of the $\mathrm{O}_{2}$ concentration 
in the water column (having a known $\mathrm{O}_{2}$ concentration) were obtained. Subsequently the inverted periscope equipped with the planar $\mathrm{O}_{2}$ sensor was lowered into the sediment, ensuring initial alignment of the sediment surface with the center of the planar optode. At the end of the measuring cycle, the planar $\mathrm{O}_{2}$ sensor was completely inserted into the anoxic part of the sediment to obtain a second calibration image. The calibrated oxygen images covered an area of $7 \times 5 \mathrm{~cm}$ or $15 \times 10 \mathrm{~cm}$, with a spatial pixel resolution of $\sim 106 \mu \mathrm{m}$ or $208 \mu \mathrm{m}$, respectively (CCD camera chip size, $640 \times 480$ pixels) (Wenzhöfer and Glud 2004). After placing the sensor foil in the sediment, images were recorded every $30-60 \mathrm{~min}$ for a total period of 12 $24 \mathrm{~h}$.

High current speeds at Sylt meant that sediment washout occurred around the periscope, and, hence, no usable images could be obtained from this site. At Hel, the dominant current component was generated by waves moving onto the shore (see Results); thus, the periscope was placed parallel to this flow. Plastic slats were also inserted into the sediment on either side of the optode to eliminate current eddies at the edge of the optode and sediment excavations around the periscope at the given conditions.

Sulfate reduction measurements - Sulfate reduction rates were measured in four intact sand cores $(36-\mathrm{mm}$ inner diameter [i.d.]) taken from the study site and then returned to the laboratory for incubation. Sulfate reduction rate measurements were performed the day after sampling at in situ temperature using a modified version of the ${ }^{35} \mathrm{~S}_{-} \mathrm{SO}_{4}^{2-}$ technique (Jørgensen 1978). The $\mathrm{SO}_{4}^{2-}$ tracer was introduced into the core either by percolation $\left(\sim 16 \mathrm{Mbq} \mathrm{L}^{-1}\right.$ ${ }^{35} \mathrm{~S}_{-} \mathrm{SO}_{4}^{2-}$ in seawater) through the core (Sylt: spring 2003) or via injection of $5 \mu \mathrm{L}$ carrier free ${ }^{35} \mathrm{~S}_{-} \mathrm{SO}_{4}^{2-}(\sim 50 \mathrm{kbq})$ through silicon ports spaced at $1-\mathrm{cm}$ intervals at the side of the core. After incubation, the sand was extruded, sliced at $1-\mathrm{cm}$ intervals, and fixed in $20 \mathrm{~mL}$ of $5 \%$ zinc acetate. The ${ }^{35} \mathrm{~S}$ present in the reduced fraction was then recovered using the cold chromium distillation procedure described by Kallmeyer et al. (2004). The radioactivity in the $\mathrm{SO}_{4}^{2-}$ and reduced fractions was determined using a Packard Tri-Carb 2900 TR or 2500 TR liquid scintillation counter. Sulfate reduction rates were calculated using the equations given in Kallmeyer et al. (2004). A subsample of the zinc acetate supernatant was also taken to determine $\mathrm{SO}_{4}^{2-}$ concentrations in the pore water.

Bottle incubations-During the 2004 field trips, bottle incubations were performed to measure the $\mathrm{O}_{2}$ consumption, $\mathrm{TCO}_{2}$ production, and changes in the solid-phase iron $[\mathrm{Fe}](\mathrm{II})$ pool in sediment horizons from different depths incubated under oxic conditions. Six sediment cores were collected from the field and immediately returned to the laboratory, where they were sliced at intervals of $0-1 \mathrm{~cm}$, $1-2 \mathrm{~cm}, 2-3 \mathrm{~cm}, 3-5 \mathrm{~cm}$, and $5-7 \mathrm{~cm}$. The slices from the same horizons were pooled, homogenized, and weighed into five $500-\mathrm{mL}$ glass bottles, which were then filled with oxic water from the study site. A subsample of each sediment horizon was frozen immediately for later analysis of Fe. The bottles were sealed with a rubber stopper and incubated at in situ temperature while rotating at $\sim 4 \mathrm{rpm}$ (lying on their side) to ensure that no anoxic zones developed within the sediment. Five samples of water for $\mathrm{O}_{2}$ and $\mathrm{TCO}_{2}$ analysis were taken from each bottle over the course of the incubation by injecting fresh seawater into the bottle (through a hypodermic needle) and simultaneously collecting the water flowing out through a second needle. At the conclusion of the incubation period (43-47 h), sediment from each bottle was collected and frozen for $\mathrm{Fe}$ analysis. Rates of $\mathrm{TCO}_{2}$ production and $\mathrm{O}_{2}$ consumption by the sediment were calculated using linear regression analysis of concentration of the solute versus time, after correcting for the addition of replacement water.

Solid-phase $\mathrm{Fe}$ profiles-Profiles of solid-phase $\mathrm{HCl}$ extractable $\mathrm{Fe}$ (II) and $\mathrm{Fe}(\mathrm{III})$ were also taken from the study sites during all field campaigns. At least five 36-mmi.d. sediment cores were taken and sliced at 1-2-cm intervals. Equivalent depth intervals from replicate cores were pooled and then frozen for later analysis of $\mathrm{Fe}$, as described below.

Sample analysis-Samples for $\mathrm{O}_{2}$ were analyzed by Winkler titration (Grasshoff 1983). $\mathrm{TCO}_{2}$ samples were measured using a UIC CM5130 acidification module in line with a CM 5012 Coulometer. Samples for Fe analysis were extracted for $1 \mathrm{~h}$ in $0.5 \mathrm{~mol} \mathrm{~L}^{-1} \mathrm{HCl}$, which was first purged with $\mathrm{N}_{2}$ to remove $\mathrm{O}_{2}$ and was then analyzed using the ferrozine method, as described by Kostka and Luther (1994). Nutrient samples were analyzed using a Skalar Continuous-Flow Analyzer according to the method of Grasshoff (1983). $\mathrm{Br}^{-}$and $\mathrm{SO}_{4}^{2-}$ were both analyzed by nonsuppressed ion chromatography; for $\mathrm{SO}_{4}^{2-}$ a Waters IC-Pak column was used with $50 \mathrm{mmol} \mathrm{L}^{-1} \mathrm{NaCl}$ and $10 \%$ methanol as the eluent, and for $\mathrm{Br}^{-}$, we used a Sykam LC A14 column with $1 \mathrm{mmol} \mathrm{L}^{-1}$ isophthalic acid as the eluent.

\section{Results}

Sediment topography - Sediment surface topographies at Sylt, as measured during the summer campaign, show only very small, irregular topographical features, with heights in the low millimeter range that do not show a clear orientation but rather form an apparently isotropic, stochastic pattern (Fig. 3a). A series of eight consecutive scans obtained over a period of 7 h (16 July 2004, 23:00 h, to 17 July 2004, 06:00 h) showed that the tidal currents induce enough shear stress, even under calm weather conditions, to redistribute the small topographical features within less than $1 \mathrm{~h}$. This, however, did not induce the formation of clear current-related features, such as ripples or scour pits, and involved only the uppermost few millimeters of the sediment. The average range $( \pm$ SD) of changes in sediment surface height along the central profile in the eight consecutive topography scans was $3.6 \pm 2.0 \mathrm{~mm}$ $(n=141)$. In contrast to the even sediment surface at Sylt, the sediment at Hel was characterized by regular, shoreparallel, and largely symmetrical ripples that were present throughout the spring campaign (Fig. 3b). Average ripple 
a) Sylt summer

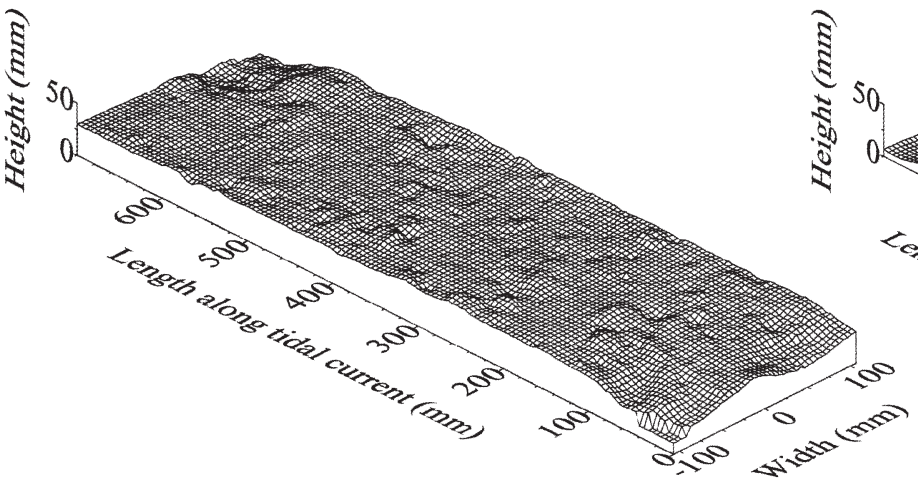

b) Hel spring

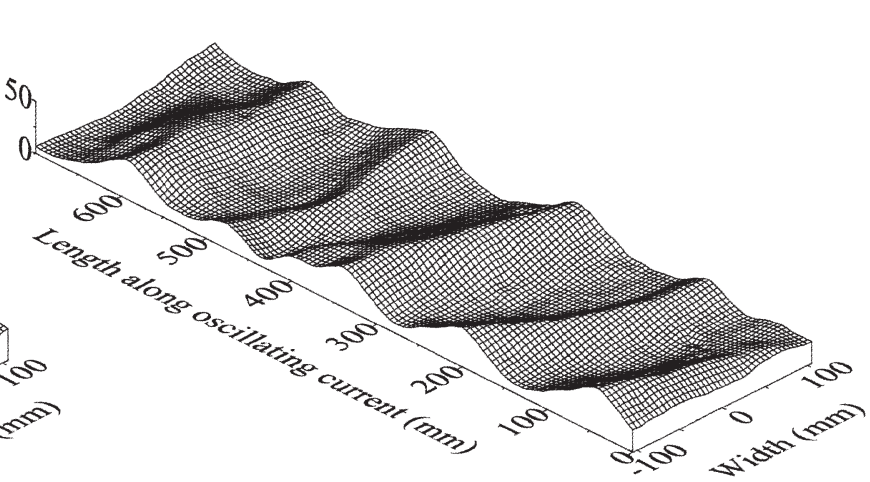

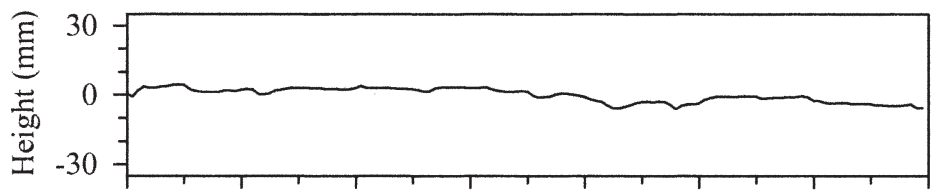

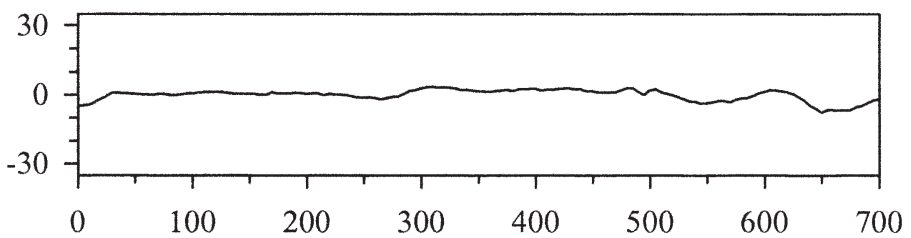

Length along tidal current $(\mathrm{mm})$
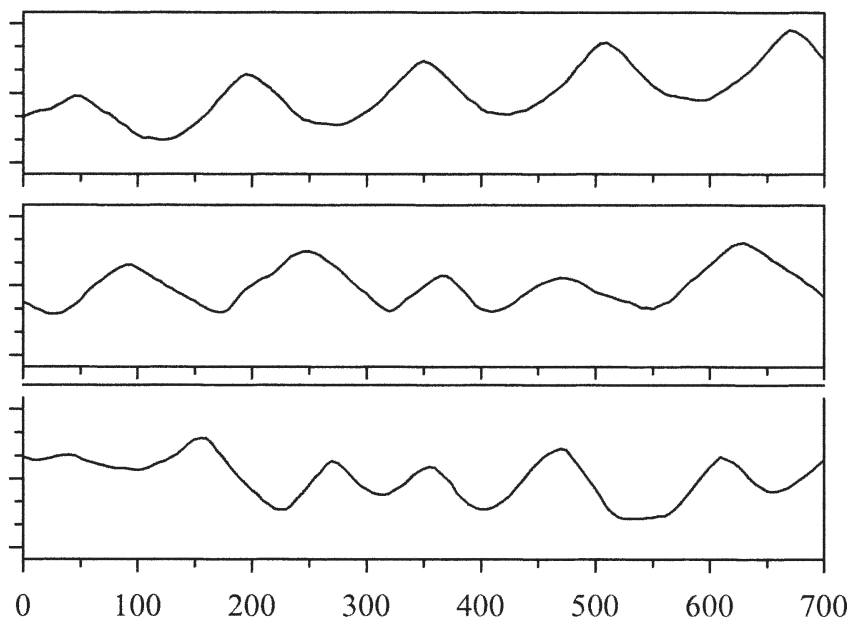

Length along oscillating current $(\mathrm{mm})$

Fig. 3. Typical examples of sediment topographies, as measured during the summer and spring field campaigns at (a) Sylt and (b) Hel, respectively. The upper graphs show typical examples of the 3D topographies obtained. The lower graphs represent further topography examples from the respective sites, depicted as surface profiles along the center line of the $3 \mathrm{D}$ surface scans in the direction of the scan.

wave length and height $( \pm \mathrm{SD})$ were, respectively, $115.6 \pm$ $28.5 \mathrm{~mm}$ and $17.5 \pm 5.1 \mathrm{~mm}(n=12)$, with maximum/ minimum wave lengths and heights of $155.1 / 73.2 \mathrm{~mm}$ and $25.2 / 10.7 \mathrm{~mm}$, respectively. Direct observations, as well as sequences of scans that were taken over the time course of several hours, indicated that almost no sediment transport and ripple movement took place under the very calm weather conditions that prevailed during the entire spring campaign. Only during short periods of slightly rougher hydrodynamics, especially on 04 May 2004 (Fig. 2c), did ripples begin to move and topographies change significantly. The symmetry of the ripple cross section and the alignment of the crests and troughs to the shoreline indicate that ripples were originally created by waves running ashore in a period of stronger hydrodynamic forcing.

Iron profiles-The total $\mathrm{HCl}$-extractable $\mathrm{Fe}$ content of the sediment was highest during summer at both sites (Fig. 4). At Sylt, clear trends in the relative $\mathrm{HCl}$-extractable $\mathrm{Fe}(\mathrm{II})$ and $\mathrm{Fe}(\mathrm{III})$ concentrations could be seen down the profiles, with $\mathrm{Fe}(\mathrm{III})$ dominating at the surface and $\mathrm{Fe}(\mathrm{II})$ comprising an increasingly greater fraction of total $\mathrm{HCl}$ extractable $\mathrm{Fe}$ down the profile. By contrast, at Hel the relative importance of $\mathrm{HCl}$-extractable $\mathrm{Fe}(\mathrm{II})$ and $\mathrm{Fe}$ (III) essentially remained the same throughout the profiles, with $\mathrm{Fe}(\mathrm{II})$ comprising the majority of total $\mathrm{HCl}$-extractable $\mathrm{Fe}$ during summer 2003. The substantial increase in the total $\mathrm{HCl}$-extractable $\mathrm{Fe}$ pool at Sylt between spring and summer most likely occurs in connection with a seasonal $50 \%$ increase in the sediment fine fraction $(<63 \mu \mathrm{m})$ between spring and summer, which was observed in both 2003 and 2004 (Hedtkamp 2005).

Sulfate reduction rates - Sulfate reduction rates were much higher at Sylt than at Hel during both summer and spring (Fig. 5). At Hel, the volumetric rates of sulfate reduction showed elevated activity near the surface during spring, while during summer the profile was characterized by uniformly low rates. At Sylt there was a distinct subsurface peak of sulfate reduction between $5 \mathrm{~cm}$ and $8 \mathrm{~cm}$ during spring, and during summer the peak moved toward the sediment surface when the maximum sulfate 

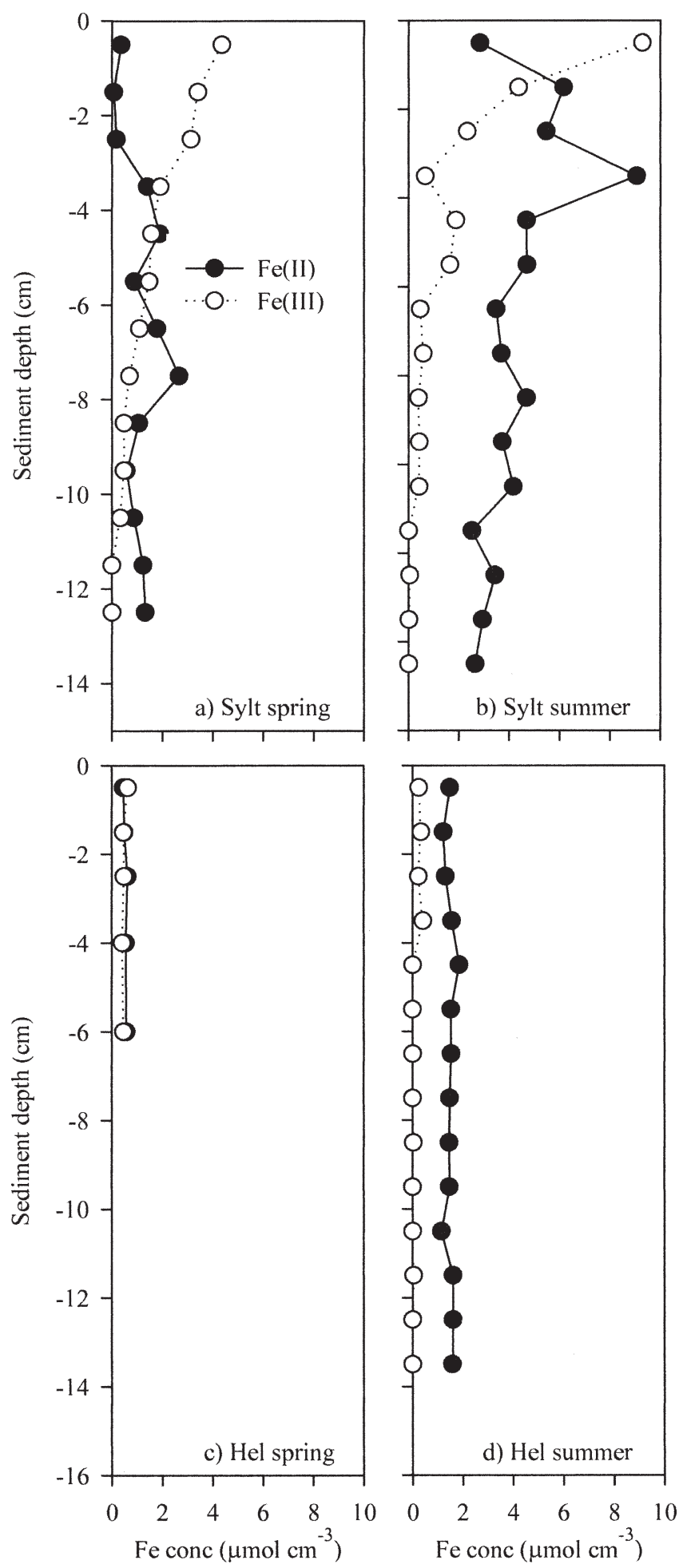

Fig. 4. Profiles of HCl-extractable Fe(II) and Fe(III) measured at (a) Sylt in spring, (b) Sylt in summer (c) Hel in spring, and (d) Hel in summer.

reduction rates were seen between $1 \mathrm{~cm}$ and $5 \mathrm{~cm}$ in depth. Integrated rates of sulfate reduction converted to $\mathrm{C}$ equivalents using a $\mathrm{C}$ : sulfur stoichiometry of $2: 1$ (Froelich et al. 1979) were 16 and $34 \mathrm{mmol} \mathrm{m}^{-2} \mathrm{~d}^{-1}$ at Sylt during

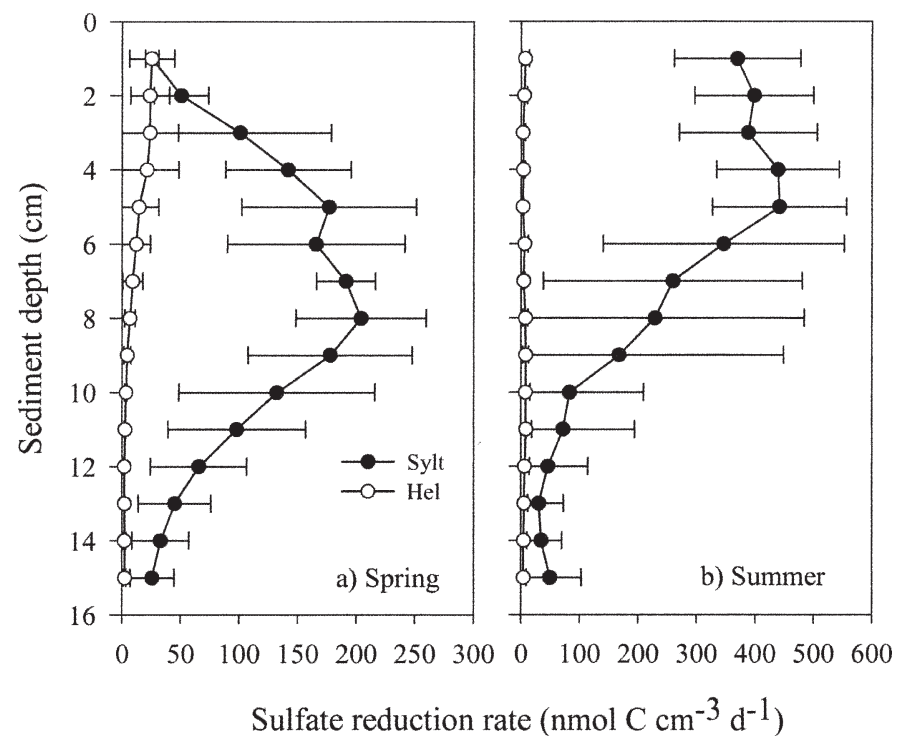

Fig. 5. Profiles of sulfate reduction rates ( $\mathrm{C}$ equivalents) measured at Sylt and Hel in (a) spring and (b) summer. The error bars represent the standard deviation of replicate cores $(n=4)$.

spring and summer, respectively. The integrated rates of sulfate reduction at $\mathrm{Hel}$, by comparison, were only 0.83 and $1.8 \mathrm{mmol} \mathrm{m}{ }^{-2} \mathrm{~d}^{-1}$ during summer and spring, respectively.

Bottle incubations-In agreement with the sulfate reduction rates, the rates of $\mathrm{O}_{2}$ consumption and $\mathrm{TCO}_{2}$ production were much higher at Sylt than at Hel (Fig. 6). At $\mathrm{Hel}$, there was a close agreement between the rates of $\mathrm{O}_{2}$ consumption and $\mathrm{TCO}_{2}$ production throughout the profile, with the highest rates of consumption/production occurring near the sediment surface. The solid-phase $\mathrm{HCl}$-extractable Fe(II) pools were $\sim 0.5 \mu \mathrm{mol} \mathrm{cm}{ }^{-3}$ throughout the profile and remained virtually unchanged at the end of the incubation. At Sylt, $\mathrm{O}_{2}$ was consumed at about twice the rate of $\mathrm{TCO}_{2}$ production throughout the profile. Rates of $\mathrm{O}_{2}$ consumption increased down the profile, reaching a maximum rate at $4 \mathrm{~cm}$ in depth. $\mathrm{TCO}_{2}$ production rates remained fairly constant throughout the profile, with the exception of a point of high production at $4 \mathrm{~cm}$ in depth. $\mathrm{HCl}$-extractable $\mathrm{Fe}(\mathrm{II})$ pools at the start of the incubation were higher at Sylt than at Hel, increasing from $1 \mu \mathrm{mol} \mathrm{cm} \mathrm{cm}^{-3}$ up to a maximum of $\sim 8 \mu \mathrm{mol} \mathrm{cm}-3$ at $5 \mathrm{~cm}$ in depth. During the incubation, the $\mathrm{HCl}$-extractable $\mathrm{Fe}$ (II) pool size decreased by between 2 and $6 \mu \mathrm{mol} \mathrm{cm}{ }^{-3}$ below $1 \mathrm{~cm}$ in depth, with the maximum decrease occurring at $4 \mathrm{~cm}$, coinciding with the maximum rates of $\mathrm{O}_{2}$ consumption and $\mathrm{TCO}_{2}$ production. Unfortunately, no measurements were performed in 2003.

Chamber incubations - There was a close agreement between the measured and modeled sediment flushing rates at Sylt, although the measured flushing rate was $\sim 15 \mathrm{~L}$ $\mathrm{m}^{-2} \mathrm{~d}^{-1}$ higher than the modeled flushing rate (Fig. 7). This offset most likely arose as a consequence of bioirrigation, which was not accounted for in the model. Given the good agreement between modeled and measured data and the high variability of the measured flushing rates, we have 


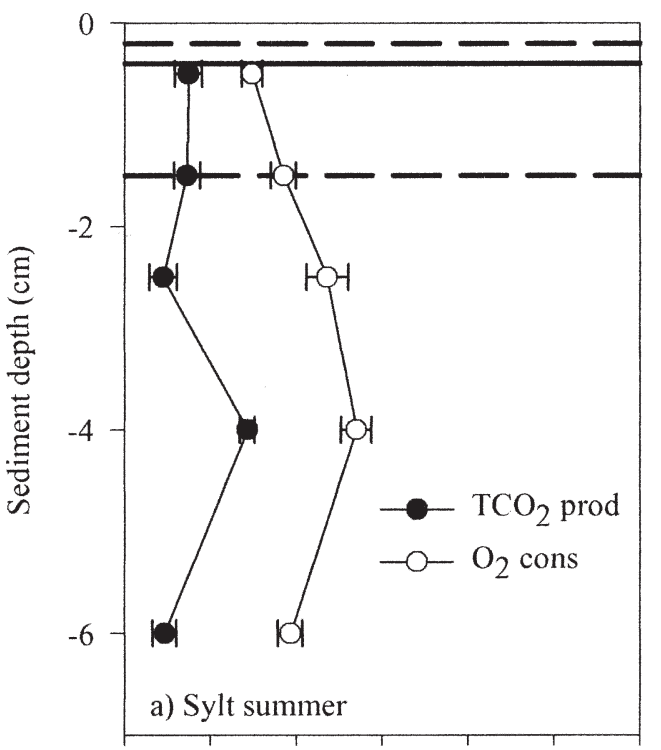

$0 \quad 500010000150002000025000300000$

$$
\mathrm{nmol} \mathrm{cm}{ }^{-3} \mathrm{~d}^{-1}
$$

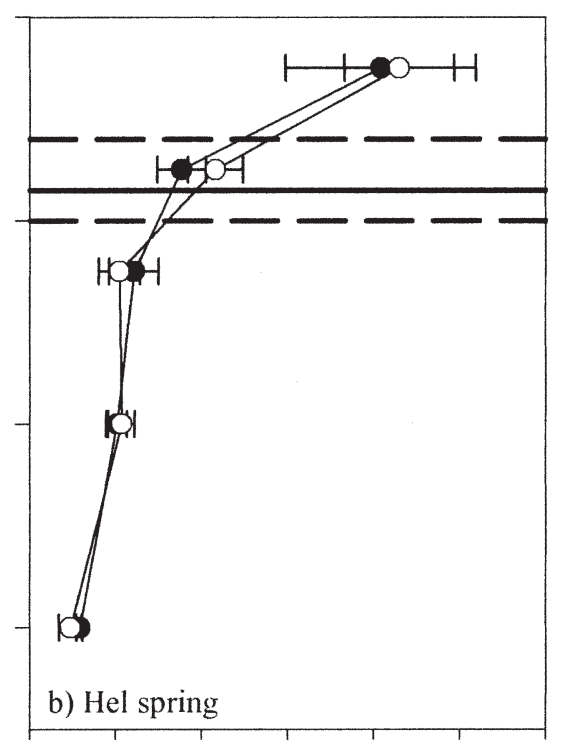

$500 \quad 1000 \quad 1500 \quad 2000 \quad 2500 \quad 3000 \quad 0$

$\mathrm{nmol} \mathrm{cm}{ }^{-3} \mathrm{~d}^{-1}$

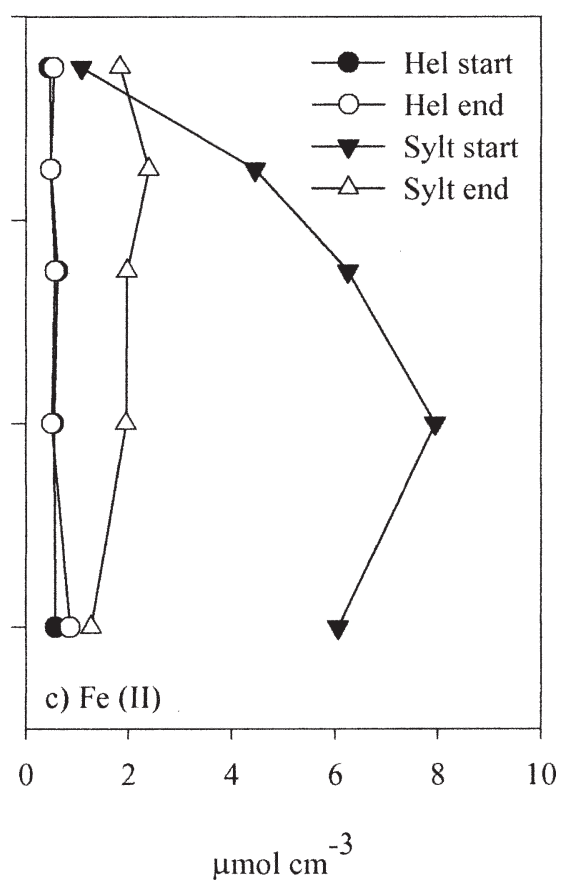

$\mu \mathrm{mol} \mathrm{cm}{ }^{-3}$

Fig. 6. Profiles of oxic $\mathrm{O}_{2}$ consumption (cons) and $\mathrm{TCO}_{2}$ production (prod) measured in bottle incubations at (a) Sylt in summer and (b) Hel in spring. (c) The change in the solid-phase HCl-extractable Fe(II) pool during the bottle incubations is also shown. Horizontal lines in (a) and (b) represent the mean (solid line), maximum, and minimum (dashed lines) measured $\mathrm{O}_{2}$ penetration depths in situ. Error bars represent the standard error about the linear regression $(n=3-4)$.

used the modeled flushing rates to constrain our solute flux measurements.

In all chamber incubations there was a clear increase in sediment $\mathrm{O}_{2}$ uptake and $\mathrm{TCO}_{2}$ release above flushing rates

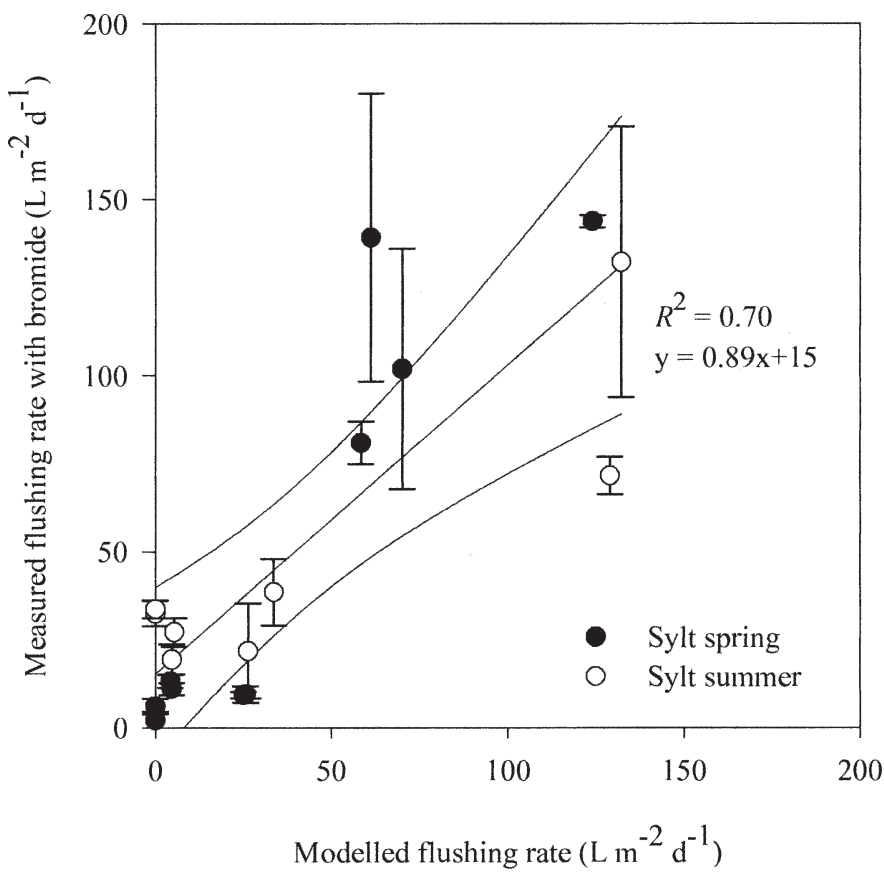

Fig. 7. The measured sediment flushing rate in chambers using bromide tracer versus the modeled sediment flushing rate described in the Materials and methods section. 95\% confidence intervals are shown. of $\sim 4-10 \mathrm{~L} \mathrm{~m}^{-2} \mathrm{~d}^{-1}$ (Fig. 8a,b,d,f). The rates of sediment $\mathrm{O}_{2}$ consumption increased by a factor of 1.6 to 2.5 between the diffusive setting and the maximum (non-resuspending) flushing rate used. Rates of $\mathrm{O}_{2}$ and $\mathrm{TCO}_{2}$ exchange at the same pressure gradient were generally higher at Sylt than at Hel when compared during the same season. For example, the Sylt $\mathrm{O}_{2}$ flux was $\sim$ two times greater at comparable sediment flushing rates in both spring and summer. At both sites, rates of $\mathrm{O}_{2}$ and $\mathrm{TCO}_{2}$ exchange were generally highest in summer. For example, $\mathrm{O}_{2}$ flux at flushing rates of 20 $60 \mathrm{~L} \mathrm{~m}^{-2} \mathrm{~d}^{-1}$ were $\sim 1.5-2$ and $\sim 1.5$ times higher during summer at $\mathrm{Hel}$ and Sylt, respectively. $\mathrm{TCO}_{2}: \mathrm{O}_{2}$ flux ratios, or apparent respiration quotient (RQ), ranged between $\sim 0.5$ and $\sim 2$, with an average of 1.2 for the whole data set. There was a consistent increase in the apparent RQ as stirring was shifted from diffusive to the lowest advective setting, followed by a more gradual decrease in the apparent RQ with increased sediment flushing rates (Fig. 8c,e,g). In general, the apparent RQs were highest under conditions of advective pore-water flushing at Sylt during summer.

Optode and microelectrode measurements - Although the $\mathrm{O}_{2}$ profiles were taken over both light and dark periods, we focus on the dark profiles here. The light profiles are considered in detail in another article addressing photosynthesis in these sediments. At both field sites, the $\mathrm{O}_{2}$ profiles were highly variable, changing between the classical diffusive profile shape commonly observed in cohesive sediments to a more irregular profile with deeper $\mathrm{O}_{2}$ penetration, reflecting the influence of transport processes other than diffusion within the sand (Fig. 9). Highly 
unusual but consistent $\mathrm{O}_{2}$ profiles were repeatedly observed on a number of electrodes (separated horizontally by $3 \mathrm{~cm}$ ) at Hel during the spring 2004 campaign, when a pool of oxygen was measured between $40 \mathrm{~mm}$ and $100 \mathrm{~mm}$ in the sediment (Fig. 9e-h). The $\mathrm{O}_{2}$ penetration depth (OPD) was highest at $\mathrm{Hel}$, ranging between $10 \mathrm{~mm}$ and $28 \mathrm{~mm}$, with an average of $17 \mathrm{~mm}(n=54$ dark profiles) in summer 2003. In spring 2004, the OPD ranged between $12 \mathrm{~mm}$ and $20 \mathrm{~mm}$, also with an average of $17 \mathrm{~mm}$ (light and dark profiles were used because of the limited data set; furthermore, photosynthesis did not have a marked effect on the OPD during this period; Fig. 10, $n=6$ profiles). At Sylt, $\mathrm{O}_{2}$ profiles were only measured in 2004, when the OPD ranged between $2 \mathrm{~mm}$ and $15 \mathrm{~mm}$, with an average of $4 \mathrm{~mm}(n=84)$. No free sulfide was detected in the pore water at either of the study sites, most likely as a consequence of coprecipitation with $\mathrm{Fe}(\mathrm{II})$.

The planar optode images show the variation of $\mathrm{O}_{2}$ penetration over ripple topography (Hel, Spring 2004), with deeper $\mathrm{O}_{2}$ penetration in the ripple troughs than at the ripple crests (Fig. 11). Image analysis revealed that the average $\mathrm{O}_{2}$ penetration depth was $16 \mathrm{~mm}$, with a range of $1.5 \mathrm{~mm}$ to $21 \mathrm{~mm}(n=20$ profiles taken, evenly spaced between the ripple crests from the images taken at 16:39 $\mathrm{h}$ and 17:03 $\mathrm{h}$ in Fig. 11).

\section{Discussion}

Biophysical site characteristics-Despite the fact that the study sites at Sylt and Hel were at a similar water depth, at relatively sheltered sites with similar grain sizes and permeability in similar climatic zones, we identified two important biophysical differences between the sites of relevance to this study. First, Sylt had higher delivery rates of labile organic carbon to the sediment, as indicated by higher Chl $a$ concentrations in the sediment (Table 1), most likely associated with high rates of benthic primary production (Wenzhöfer unpubl. data). This ultimately led to higher sediment $\mathrm{O}_{2}$ consumption and $\mathrm{TCO}_{2}$ production rates at Sylt compared to Hel (Figs. 6, 8). Secondly, currents at Sylt were high and unidirectional (Fig. 2a) but did not create pronounced topographies at the sediment surface (Fig. 3). This is not unusual, as the formation of surface topographies upon hydrodynamic forcing is dependent on several factors, including direction and strength of currents and waves as well as sediment properties ( $\mathrm{Li}$ and Amos 1998). A similar observation, with strong currents eroding the sediment surface topography rather than creating roughness elements, has also been reported at other sites (Wheatcroft 1994). By contrast, at Hel, bottom currents were much lower than at Sylt (Fig. 1). However, the dominating, wave-driven oscillating component at $\mathrm{Hel}$ was facing well-defined ripples (Fig. 3). The interaction between bottom currents and topography is a key driver of advective pore-water and solute exchange (Huettel and Webster 2001), and one would expect that the absence of topography at Sylt would have greatly limited advective pore-water exchange compared to Hel, where well-formed topography was present. We now proceed to discuss the data, taking into consideration these important differences in site characteristics.

$\mathrm{O}_{2}$ distribution within the sediment-The effect of rippled sediment topography on sediment $\mathrm{O}_{2}$ distribution is graphically illustrated by planar optode images of oxygen distribution taken in situ at Hel; these images closely resemble those observed by Precht et al. (2004) beneath a rippled sediment surface in a laboratory-based wave tank study. The deeper $\mathrm{O}_{2}$ penetration at the ripple trough reflects increased $\mathrm{O}_{2}$ transport into the sediment through advective intrusion of bottom water into the sediment, while the shallow $\mathrm{O}_{2}$ penetration at the ripple crests is caused by an outflow of anoxic pore water at that point (Webb and Theodor 1968; Precht and Huettel 2004). The time-lapse sequence further shows the oxic front moving through the sediment as a result of ripple migration causing an oscillation between oxygenated and reduced conditions at a given sediment location over short time periods. One of the major concerns of the planar optode measurements is the possibility that periscope placement into the sediment will disrupt the true in situ $\mathrm{O}_{2}$ distribution. This is particularly pertinent in permeable sediments, where current interactions with such a large object may well induce abnormal advective flow patterns within the sediment. It is difficult to quantitatively evaluate this effect; however, parallel microprofile and planar optode measurements essentially resolved the same range and average $\mathrm{O}_{2}$ penetration depths $(16 \mathrm{~mm}$ for the planar optode and $17 \mathrm{~mm}$ using the electrode).

The $\mathrm{O}_{2}$ profiles at both Sylt and Hel illustrate the timedependent influence of sand (Sylt) and ripple (Hel) migration and advection on the $\mathrm{O}_{2}$ distribution within the sediment. $\mathrm{O}_{2}$ profiles influenced by advection have also been observed in North Sea sediments by Lohse et al. (1996), who reported $\mathrm{O}_{2}$ penetration depths in excess of $50 \mathrm{~mm}$ measured in freshly retrieved sediment cores. The $\mathrm{O}_{2}$ profiles measured at $\mathrm{Hel}$ in 2004 (Fig. 9e-h) showed subsurface maxima, resembling profiles influenced by bioirrigating macrofauna (Meysman et al. 2005). However, faunal surveys (Kotwicki unpubl. data) showed that large pumping macrofauna were not present at the field site, indicating that the interplay between pulses of deep advective oxygen injection into the sand and uneven oxygen consumption rates within the sediment led to these unusual profiles. To check the plausibility of this explanation we used a simple one-dimensional reactive transport model to simulate the time-dependent $\mathrm{O}_{2}$ concentration within the sediment after the introduction of $\mathrm{O}_{2}$ to a depth of $120 \mathrm{~mm}$. The model was set up using the program COMSOL Multiphysics (www.comsol.com), with a subdomain length of $180 \mathrm{~mm}$ and an element resolution of $0.5 \mathrm{~mm}$. The upper boundary condition was the $\mathrm{O}_{2}$ concentration in the water column. $\mathrm{O}_{2}$ consumption within the sediment was modeled using monod kinetics, with a half-saturation constant of $5 \mu \mathrm{mol} \mathrm{L} \mathrm{L}^{-1}$. The maximum rate constant within the subdomain was defined as a function of depth fitted to the measured $\mathrm{O}_{2}$ consumption rate within the sediment at Hel in spring 2004 (see Fig. 6). 

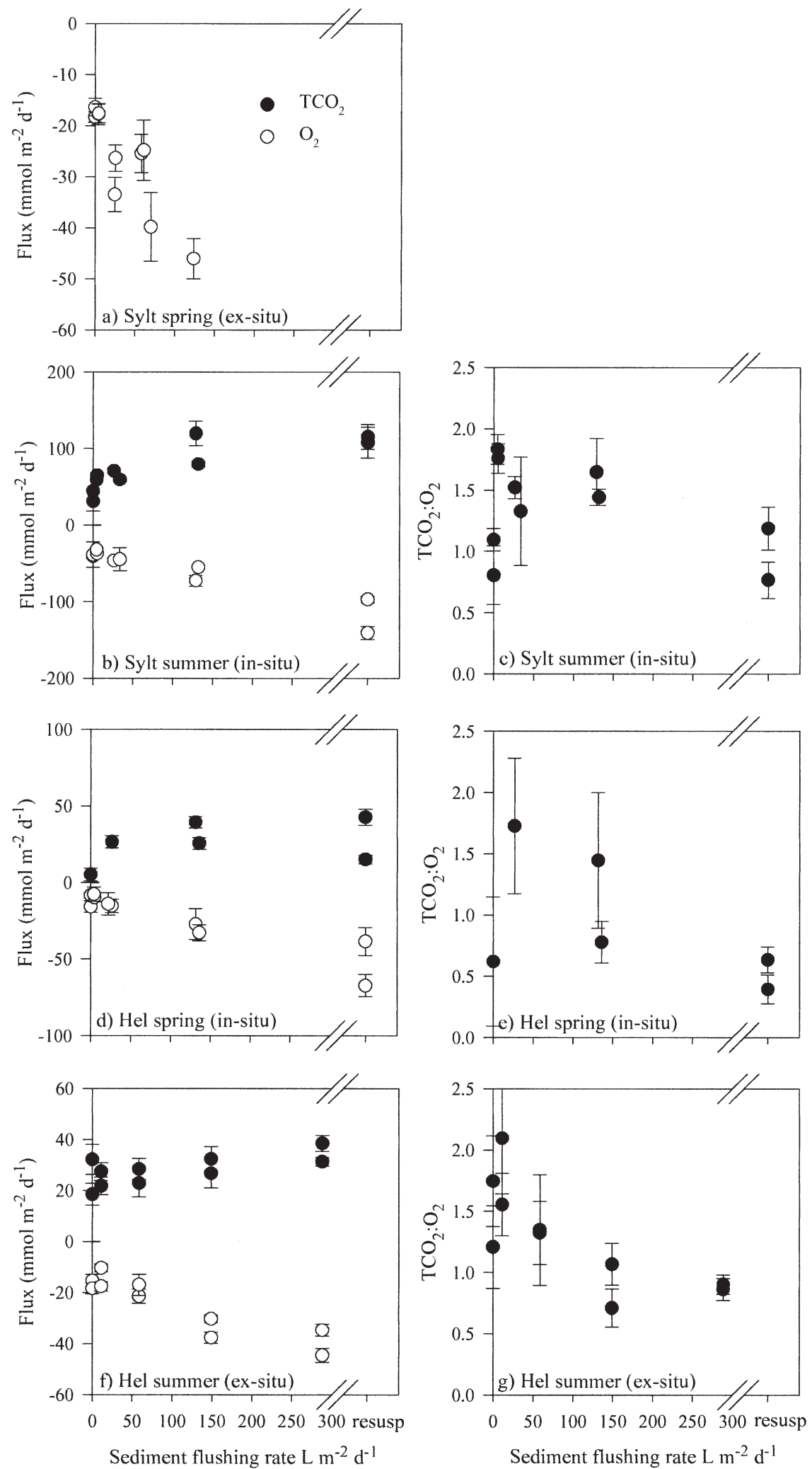

Fig. 8. (a, b, d, f) The measured fluxes of $\mathrm{O}_{2}$ and $\mathrm{TCO}_{2}$ across the sediment-water interface and $(\mathrm{c}, \mathrm{e}, \mathrm{g})$ the ratio of the $\mathrm{TCO}_{2}: \mathrm{O}_{2}$ flux measured at Sylt and $\mathrm{Hel}$ in benthic chambers at different advective pore-water flushing rates. Different pore-water flushing rates were induced by varying the chamber stirring speed between $20 \mathrm{rpm}$ and $80 \mathrm{rpm}$. A sediment flushing rate of 0 refers to benthic chambers that were stirred at $20 \mathrm{rpm}$ back and forth on an alternating 15-s 
The model simulations show that if a pulse of oxic water were to be advected $120 \mathrm{~mm}$ into the sediment at $\mathrm{Hel}$ during spring 2004, then at 20-mm sediment depth, $\mathrm{O}_{2}$ would be completely consumed within $6 \mathrm{~h}$. However, as a result of lower sediment $\mathrm{O}_{2}$ consumption rates below $20 \mathrm{~mm}$ in depth, a pool of $\mathrm{O}_{2}$ can remain for $>10 \mathrm{~h}$ between a sediment depth of 40 and $100 \mathrm{~mm}$ (Fig. 12), resulting in profiles that bear a close resemblance to those observed in situ. Nevertheless, it is apparent that the modeled profiles were less persistent than those observed in situ. As discussed below, this is most likely because the sediment $\mathrm{O}_{2}$ consumption rates measured in the bottle incubations are an overestimate compared to those occurring at depth in situ; in this case we suggest that the cause is primarily mechanical homogenization (e.g., Kostka et al. 1999). The exact cause of the initial $\mathrm{O}_{2}$ penetration so deep into the sediment remains unclear. Storm events would quite likely lead to $\mathrm{O}_{2}$ penetration to depths of $10 \mathrm{~cm}$ into the sediment through resuspension and increased advection. There were, however, no storm events in the week prior to our measurements, thus ruling this explanation out. During the field campaign we observed a number of benthic fish species, including sand eels, which have been shown to ventilate $\mathrm{O}_{2}$ into the sediment (Behrens et al. 2007). We therefore speculate that the ventilation of the sediment by bottom-dwelling fish may explain the deep $\mathrm{O}_{2}$ pool observed here. Regardless of the exact cause, the model simulation showed that an episodic injection of $\mathrm{O}_{2}$ into the sediment will result in a relatively stable subsurface $\mathrm{O}_{2}$ pool, as we observed repeatedly in the field.

Sediment biogeochemistry and the balance between net oxidation and reduction-Oxic respiration and sulfate reduction are generally considered to be the main pathways of organic matter degradation in coastal sediments; however, other metabolic pathways, including denitrification and dissimilatory $\mathrm{Fe}$ reduction, may make major contributions in some environments (Canfield et al. 2005). Measurements of denitrification showed that this process made a negligible contribution to total mineralization at both study sites, Sylt and Hel (Wenzhöfer and Glud unpubl. data). We did not measure Fe reduction in this study; however, a number of studies have shown that the contribution of $\mathrm{Fe}$ reduction to total $\mathrm{C}$ oxidation (in individual depth intervals) is strongly dependent on the poorly crystalline Fe(III) content of the sediment (Thamdrup 2000; Gribsholt et al. 2003; Jensen et al. 2003). This relationship can be approximated by the empirical relationship

$$
\% \mathrm{Fe} R=100 \% \times\left(1-e^{-[\mathrm{Fe}(I I I)] \times 0.056}\right)
$$

where $\% \mathrm{FeR}$ is the $\%$ carbon oxidation via $\mathrm{Fe}$ reduction and $[\mathrm{Fe}(I I I)]$ is the concentration of poorly crystalline solidphase Fe oxides (Gribsholt et al. 2003; Jensen et al. 2003). Assuming that $\mathrm{HCl}$-extractable $\mathrm{Fe}(\mathrm{III})$ provides a reasonable proxy for poorly crystalline $\mathrm{Fe}$ (III) within the sediment, then one would expect Fe reduction to contribute a maximum of $\sim 40 \%$ to total carbon oxidation in the surface $1 \mathrm{~cm}$ of sediment at Sylt during summer, when the highest concentration of $\mathrm{HCl}$-extractable $\mathrm{Fe}(\mathrm{III})$ was measured $(9 \mu \mathrm{mol} \mathrm{cm}-3)$. Aside from this one occasion, the concentration of $\mathrm{HCl}$-extractable $\mathrm{Fe}(\mathrm{III})$ observed was generally in the range of $\sim 1-4 \mu \mathrm{mol} \mathrm{cm}{ }^{-3}$, corresponding to an expected contribution of $\sim 5-20 \%$ Fe reduction to total carbon oxidation. Therefore, on a depth-integrated basis we estimate that Fe reduction contributes a maximum of 10-20\% of total carbon oxidation at our study sites. This finding is also in agreement with that of Slomp et al. (1997), who concluded that $\mathrm{Fe}$ reduction made a minor contribution to $\mathrm{C}$ oxidation in sandy North Sea sediments.

The contribution of sulfate reduction to total mineralization within the sediment can be estimated by comparing the integrated sulfate reduction rates measured in the core incubations to the $\mathrm{TCO}_{2}$ production rates measured in chamber incubations. In this study such a comparison is complicated by the possibility that core incubations may overestimate rates of sulfate reduction as a result of a reduced transport of $\mathrm{O}_{2}$ into the sediment upon removal of the cores from the natural environment. This problem is not likely to have been significant at Sylt, where the in situ $\mathrm{O}_{2}$ penetration depth averaged only $4 \mathrm{~mm}$, and, therefore, artificially high rates are only likely to have been measured in the top $1 \mathrm{~cm}$ of sediment. At Hel, where periodically deep $\mathrm{O}_{2}$ penetration was observed in situ, the rates measured might be considered a maximum estimate. Using the range of $\mathrm{TCO}_{2}$ production rates, we can estimate that sulfate reduction contributed to between $35 \%$ and $90 \%$ of organic matter degradation at Sylt and $2-30 \%$ at Hel. Given that the in situ $\mathrm{TCO}_{2}$ exchange rates at Hel are likely to fall in the upper range of those measured in the chambers (while at Sylt they are likely to fall in the lower range; see following discussion), we speculate that the in situ contributions are most likely to be closer to $\sim 90 \%$ at Sylt and $\sim 2 \%$ at Hel. At Sylt, the $\mathrm{SO}_{4}^{2-}$ content of the pore waters was $\sim$ fivefold higher than at $\mathrm{Hel}$ as a result of the salinity differences. The $\mathrm{SO}_{4}^{2-}$ concentrations within the pore waters at Hel were, however, always in excess of 1$2 \mathrm{mmol} \mathrm{L}-1$, which is well above reported half-saturation concentrations for sulfate-reducing bacteria (e.g., Roychoudhury et al. 2003), ruling out $\mathrm{SO}_{4}^{2-}$ limitation as the explanation for this difference. We suggest that this difference arose as consequence of greater $\mathrm{O}_{2}$ availability in the sediments at $\mathrm{Hel}$ as a consequence of lower $\mathrm{O}_{2}$

cycle; resusp refers to chambers stirred at $160 \mathrm{rpm}$, which induced sediment resuspension. Error bars in panels $\mathrm{a}, \mathrm{b}, \mathrm{d}$, and $\mathrm{f}$ represent the standard error about the regression of solute concentration versus time $(n=3-4)$; error bars in panels $\mathrm{c}$, e, and g represent the standard error described previously, propagated through the calculation of $\mathrm{TCO}_{2}: \mathrm{O}_{2}$. Data points for which the standard error is greater than the value are not shown. 

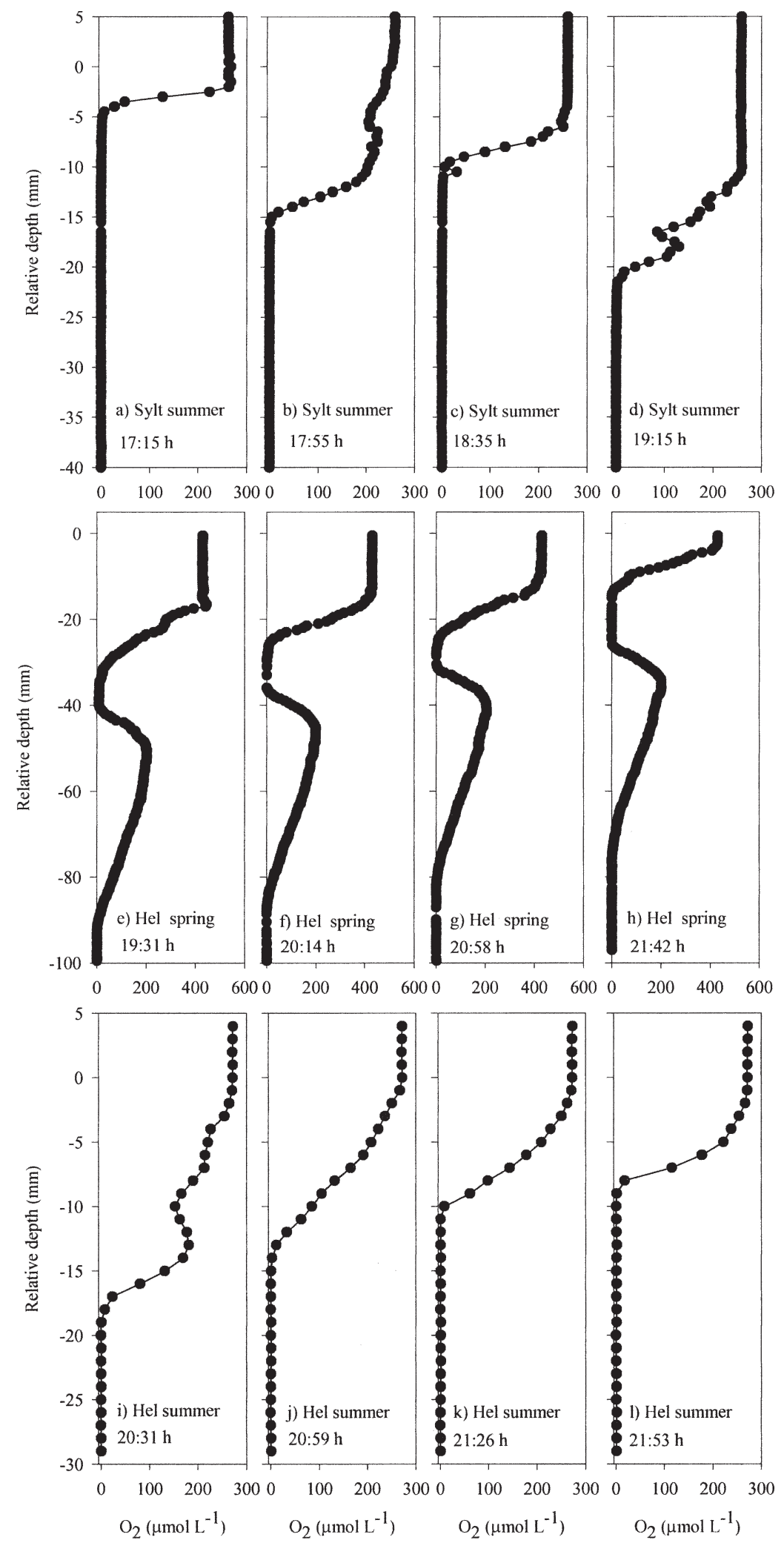

Fig. 9. A selection of in situ $\mathrm{O}_{2}$ profiles measured during the field campaigns at (a-d) Sylt summer 2004, (e-h) Hel spring 2004, and (i-1) Hel summer 2003. Times are shown as hours:minutes. 


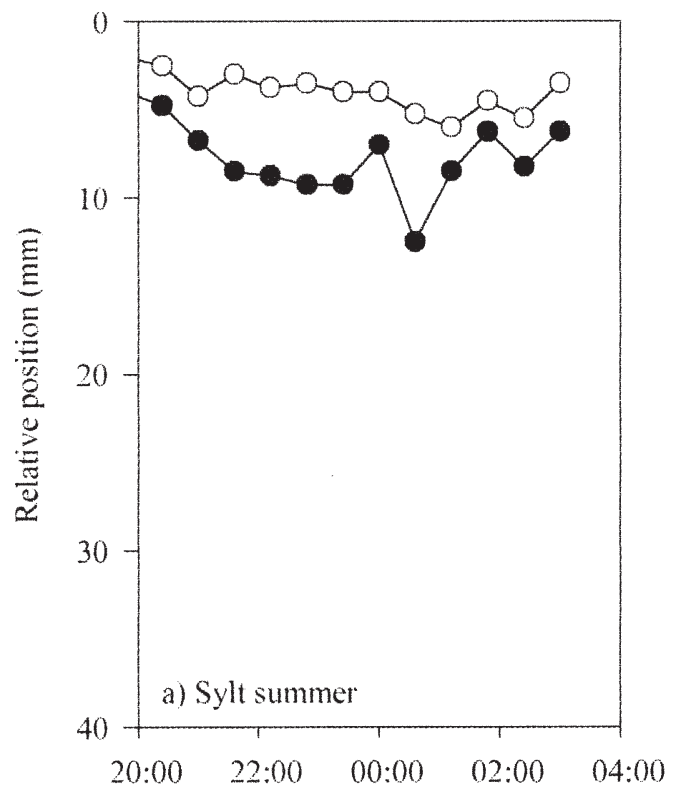

Time of day (hh:mm)

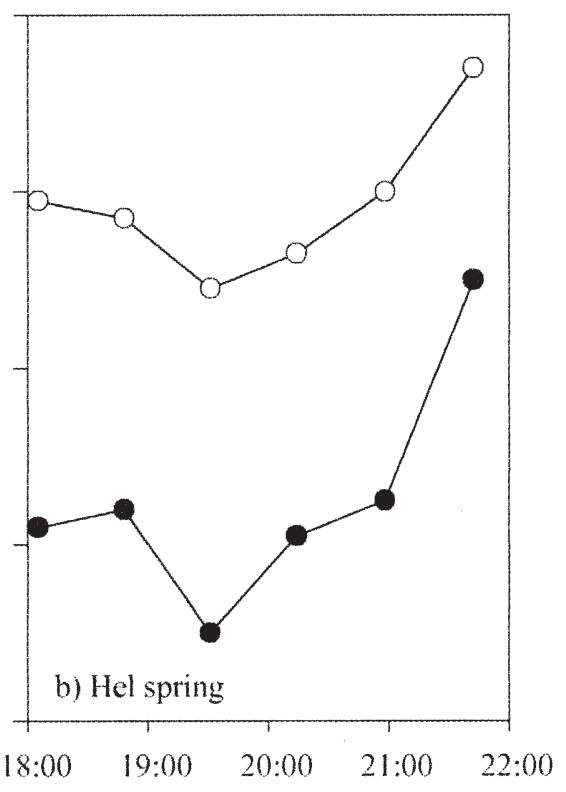

Time of day (hh:mm)

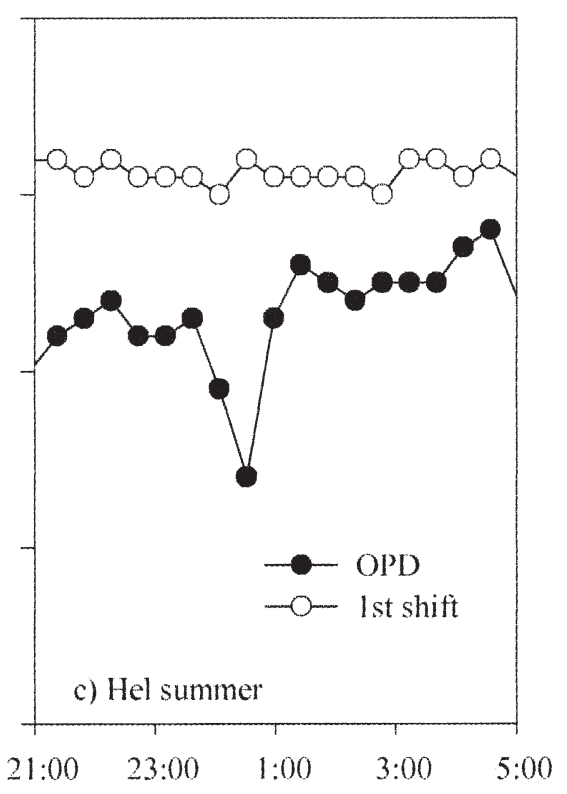

Time of day (hh:mm)

Fig. 10. In situ $\mathrm{O}_{2}$ penetration depths within the sediment, calculated as the distance between the first change in the $\mathrm{O}_{2}$ concentration at the sediment surface (first shift) and the anoxic zone of the sediment. Times are presented as time of the day in $24-\mathrm{h}$ time (hours:minutes).

consumption rates (two to three times lower) and higher rates of $\mathrm{O}_{2}$ advection into the sediments, limiting growth of sulfate reducers (see following discussion) at this site.

Consistent with the high rates of sulfate reduction at Sylt, there was generally an excess of $\mathrm{TCO}_{2}$ produced relative to $\mathrm{O}_{2}$ consumed, with a $\mathrm{TCO}_{2}: \mathrm{O}_{2}$ ratio (apparent $\mathrm{RQ})$ of $\sim 1.5$ being measured in the chamber incubations (Fig. 8c). A combination of the bottle incubation, sulfate reduction, and in situ $\mathrm{O}_{2}$ profiling data also gave the same estimate (Table 2, see $\mathrm{O}_{2}$ consumption and solute exchange in situ for details), indicating that there was a net build-up of reduced solutes within the sediment, as described by Canfield et al. (2005). Consistent with this explanation, there was a significant pool of reduced $\mathrm{HCl}$-extractable $\mathrm{Fe}(\mathrm{II})$ within the sediment during summer, which was substantially greater than that observed during spring in 2003 (Fig. 4).

In order to maintain steady state over an annual cycle, there must be a net reoxidation of sulfides at some point. The bottle incubations conducted here showed that the $\mathrm{HCl}$-extractable $\mathrm{Fe}(\mathrm{II})$ pool decreased rapidly upon exposure to $\mathrm{O}_{2}$ and that two to four times more $\mathrm{O}_{2}$ was consumed than $\mathrm{TCO}_{2}$, indicating the rapid reoxidation of $\mathrm{FeS}$ upon sediment resuspension. In agreement with this, the chambers run at $160 \mathrm{rpm}$, inducing sediment resuspension during summer, also showed a drop in the $\mathrm{TCO}_{2}: \mathrm{O}_{2}$ ratio, in one case to $\sim 0.8$ (Fig. $8 \mathrm{c}$ ). As such, it seems highly likely that the reduced pool of sulfides accumulated over the summer period in the deeper sediment layers becomes reoxidized in the winter months, when storms resuspend the sediment to a greater extent than during summer. Indeed, it has been observed that parameters such as the sediment fine fraction and sediment permeability change over the winter months at the study site on Sylt in connection with increased wind speeds (Hedtkamp 2005). Consistent with the low sulfate reduction rates measured at $\mathrm{Hel}$, there was no change in the $\mathrm{HCl}$-extractable $\mathrm{Fe}(\mathrm{II})$ pool size, and the bottle experiments showed a very close to $1: 1$ relationship between $\mathrm{O}_{2}$ consumption and $\mathrm{TCO}_{2}$ production. Thus, at Hel, virtually all of the organic matter was oxidized, with $\mathrm{O}_{2}$ as the immediate terminal electron acceptor, whereas at Sylt, organic matter oxidation was primarily anoxic, with the sulfur cycle providing an intermediate shunt for electrons and thus temporally decoupling $\mathrm{O}_{2}$ consumption and $\mathrm{TCO}_{2}$ production. At this point we should note that the previous discussion assumes that the dissolution and precipitation of $\mathrm{CaCO}_{3}$ was negligible in situ, which is reasonable to assume in sediments with a low carbonate content (Mackin and Swider 1989), as was the case here.

$\mathrm{O}_{2}$ consumption and solute exchange in the chamber incubations - In the chambers used here, the advective porewater flow pattern occurring within the sediment has been well characterized (Huettel and Gust 1992; Khalili et al. 1997), and we used a simple model to calculate the advective flow of water across the sediment-water interface within the chambers (see Materials and methods). Of particular interest to this study was the extent to which $\mathrm{O}_{2}$ advected into the sediment was consumed, compared to that simply recirculated through the sediment. To correct for 'nonadvective' $\mathrm{O}_{2}$ consumption, we subtracted the benthic $\mathrm{O}_{2}$ fluxes in the 'diffusive chambers' from the fluxes in the stirred (or flushed chambers) to obtain an estimate of the purely advective component of the sediment $\mathrm{O}_{2}$ consumption, compared to the calculated transport of $\mathrm{O}_{2}$ 

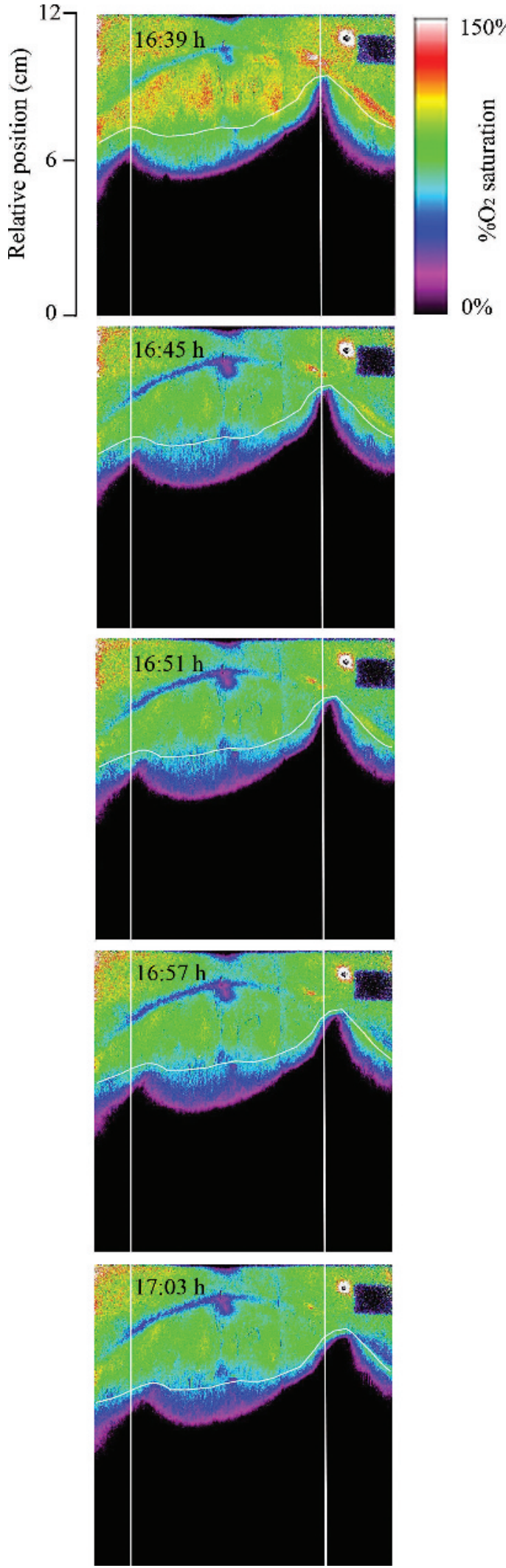

Fig. 11. A series of planar optode images showing in situ $\mathrm{O}_{2}$ distribution around ripples measured at Hel on 04 May 2004. The vertical white lines are included to emphasize the horizontal movement of the ripple. The areas of abnormal $\mathrm{O}_{2}$ concentrations

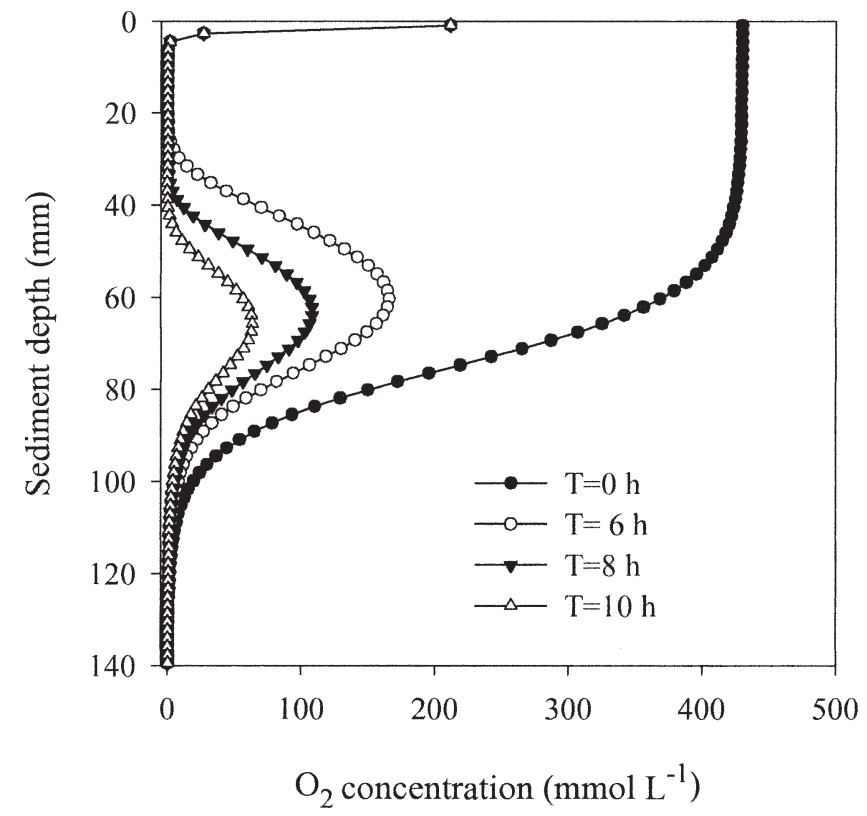

Fig. 12. The modeled time-dependent change in $\mathrm{O}_{2}$ concentration within the sediment at Hel in spring, following a theoretical advective injection of $\mathrm{O}_{2}$-rich water into the sediment ( $\mathrm{T} 0$ ), and its subsequent consumption over time ( $\mathrm{T}=6-10 \mathrm{~h})$.

into the sediment based on $\mathrm{O}_{2}$ concentrations in the water column and the volume of water flushed through the sediment (Fig. 13). It can be seen that at both sites there was a strong correlation between the increased flushing of $\mathrm{O}_{2}$ into the sediment and the advective component of sediment $\mathrm{O}_{2}$ consumption. Based on the slopes of the regressions, on average of $\sim 70 \%$ and $\sim 30 \%$ of the $\mathrm{O}_{2}$ advected into the sediments was actually consumed at Sylt and $\mathrm{Hel}$, respectively. The increase in the $\mathrm{O}_{2}$ consumption rate due to advective transport is dependent on both the residence time of water advected through the sediment and also the volumetric $\mathrm{O}_{2}$ consumption rate of the sediment (Rutherford et al. 1995), and so the much greater fraction of the $\mathrm{O}_{2}$ advected through the sediment that was consumed at Sylt (compared to Hel) is consistent with the higher volumetric rates of $\mathrm{O}_{2}$ consumption at that site. Thus, in sediments with lower mineralization rates, advective pore-water transport will have a more limited effect on sediment $\mathrm{O}_{2}$ consumption rates than in sediments with higher mineralization rates. Because the residence time of water in the sediment is the other critical factor influencing sediment $\mathrm{O}_{2}$ uptake rates, it can be expected that there will be a certain flushing rate above which sediment $\mathrm{O}_{2}$ uptake will increase very little. The magnitude of this flushing rate will depend on the average path length of the advective flow field, which will in turn depend primarily on the shape of sediment topography and also the sediment respiration rate (higher respiration rates would lead to higher critical flushing speeds, with correspondingly

in the overlying water were caused by mechanical damage to the sensor foils during emplacement of the periscope. 
Table 2. The maximum ( $\max$ ) and minimum (min) rates of $\mathrm{O}_{2}$ consumption (cons) and $\mathrm{TCO}_{2}$ production (prod) measured during the 2004 field campaigns in chamber incubations (non-resuspended). For comparison, the in situ $\mathrm{O}_{2}$ consumption and TCO $\mathrm{T}_{2}$ production estimated using volumetric respiration rates measured in bottle incubations integrated over the maximum, minimum, and average in situ $\mathrm{O}_{2}$ penetration depths (given in the Results section and shown in Fig. 6) are also presented (bottle/O $\mathrm{O}_{2}$ penetration). It was assumed that the volumetric consumption/production rate in each slice was constant where $\mathrm{O}_{2}$ did not penetrate through the full depth of a slice and that the integrated rate was scaled linearly to the oxic depth of that slice. The estimates of $\mathrm{TCO}_{2}$ production are based on the measured rates of sulfate reduction integrated over the anoxic zone of the sediment and the $\mathrm{TCO}_{2}$ production rate in the bottle incubations integrated over the oxic zone of the sediment. The diffusive supply of $\mathrm{O}_{2}$ to the sediment was calculated using $\mathrm{FO}_{2}=\sqrt{2 D_{s} R_{O_{2}}\left[\mathrm{O}_{2}\right]}$, where $D_{s}$ is the sediment diffusivity, $R_{O_{2}}$ is the $\mathrm{O}_{2}$ consumption rate measured in bottle incubation, and [ $\left.\mathrm{O}_{2}\right]$ is concentration of $\mathrm{O}_{2}$ in the water column (Cai and Sayles 1996). All units are mmol m-2 $\mathrm{d}^{-1}$.

\begin{tabular}{|c|c|c|c|c|}
\hline & \multicolumn{2}{|c|}{ Sylt summer $2004 *$} & \multicolumn{2}{|c|}{ Hel spring 2004} \\
\hline Min $\mathrm{O}_{2}$ cons & 32 & 13 & 8 & \multirow{4}{*}{$\begin{array}{l}25 \\
33 \\
29\end{array}$} \\
\hline Average $\mathrm{O}_{2}$ cons & - & 29 & - & \\
\hline $\mathrm{O}_{2}$ diffusive supply & \multicolumn{2}{|c|}{11} & & \\
\hline Min $\mathrm{TCO}_{2}$ prod & 31 & 36 & 5 & \\
\hline
\end{tabular}

* Sylt, Island of Sylt; Hel, Hel Peninsula.

higher sediment $\mathrm{O}_{2}$ consumption rates). An assessment of the interaction between these factors is beyond the scope of this article; however, such a study would lend itself well to numerical simulation analysis.

As well as affecting the absolute exchange rates, flushing also affected the relative rates of $\mathrm{O}_{2}$ and $\mathrm{TCO}_{2}$ exchange and, hence, the apparent respiration quotient (Fig. 8). The effect of flushing on the apparent RQ is somewhat harder to conceptualize than that for the absolutes fluxes, and we suggest that the observed increase, and then the decrease, in the apparent RQ was a complex interaction of a number of factors, including transport phenomena and geochemistry. First, the $\mathrm{O}_{2}$ and $\mathrm{TCO}_{2}$ concentration gradients exist on very different spatial scales, with $\mathrm{O}_{2}$ concentration gradients existing on the order of millimeters, while the $\mathrm{TCO}_{2}$ gradient exists on the order of centimeters to meters. If these gradients are perturbed from equilibrium, then re-equilibration of the gradients and, hence, fluxes will occur on very different timescales, ranging from minutes to hours for $\mathrm{O}_{2}$ and from days to weeks for solutes with concentration gradients on the order of centimeters (Jahnke et al. 2000; Cook et al. 2006) when diffusion is the dominant transport process. As such, when a permeable sediment previously subjected to advective pore-water flow is enclosed within a diffusive environment, $\mathrm{O}_{2}$ fluxes will re-equilibrate to the diffusive transport regime on the order of hours, while $\mathrm{TCO}_{2}$ fluxes will take days to weeks to readjust to the new transport regime. Over the short term, in benthic chamber incubations this would result in relatively higher $\mathrm{O}_{2}$ fluxes compared to $\mathrm{TCO}_{2}$, consistent with the relatively low apparent RQs observed in the diffusive chamber incubations (Fig. 8c,e,g). If higher than normal flushing rates are imposed, then the increased depth of $\mathrm{O}_{2}$ penetration into the sediment may induce the reoxidation of reduced solutes and thus lower the observed apparent RQs, as was observed in our chamber incubations (Fig. 8c,e,g). Thus, apparent RQs measured in sandy sediments may be affected by an interaction between changes in transport regime and geochemistry, meaning that great caution should be exercised when interpreting apparent RQs in permeable sediments, particularly when no information on their variation with sediment flushing rate is available.

$\mathrm{O}_{2}$ consumption and solute exchange in situ-The volumetric sediment respiration rates estimated from the bottle incubations in combination with the $\mathrm{O}_{2}$ penetration depths measured in situ provide another means of estimating the sediment respiration rates. The bottle incubations used to measure respiration have a number of potential shortcomings, which we will now discuss briefly. First, homogenization and mechanical disruption of microscale heterogeneity (as was induced by bottle movement) may stimulate respiration (Kostka et al. 1999; Hansen et al. 2000). Secondly, introducing $\mathrm{O}_{2}$ into previously anoxic sediments will greatly perturb the sediment chemical and biological conditions, potentially stimulating $\mathrm{TCO}_{2}$ production through the abrupt dissolution of carbonates, as a consequence of sulfide reoxidation (Green and Aller 2001), and/or the death and subsequent mineralization of obligate anaerobic bacteria. Here we only used the rates measured in the top 1-2 cm of sediment (in situ aerobic depth), which are likely to experience regular (Hel) and almost-constant (Sylt) resuspension, leading to mechanical stress and exposure to $\mathrm{O}_{2}$ of the sediment microenvironment. As such, we do not consider that the incubation conditions in the bottles differed greatly from those in situ for the surface $\sim 1-2 \mathrm{~cm}$ layers of sediment. Deeper within the sediment, where mixing and oxic conditions occur less frequently, the oxic and mechanically disturbed conditions used in our incubations are likely to lead to large differences in $\mathrm{TCO}_{2}$ production rates compared to those occurring under undisturbed, anoxic conditions. Strong evidence for this comes from the fact that the measured rates of $\mathrm{TCO}_{2}$ production in the bottle incubations were $\sim 10$-fold higher than those expected from the sulfate reduction rates measured in cores. Similar 


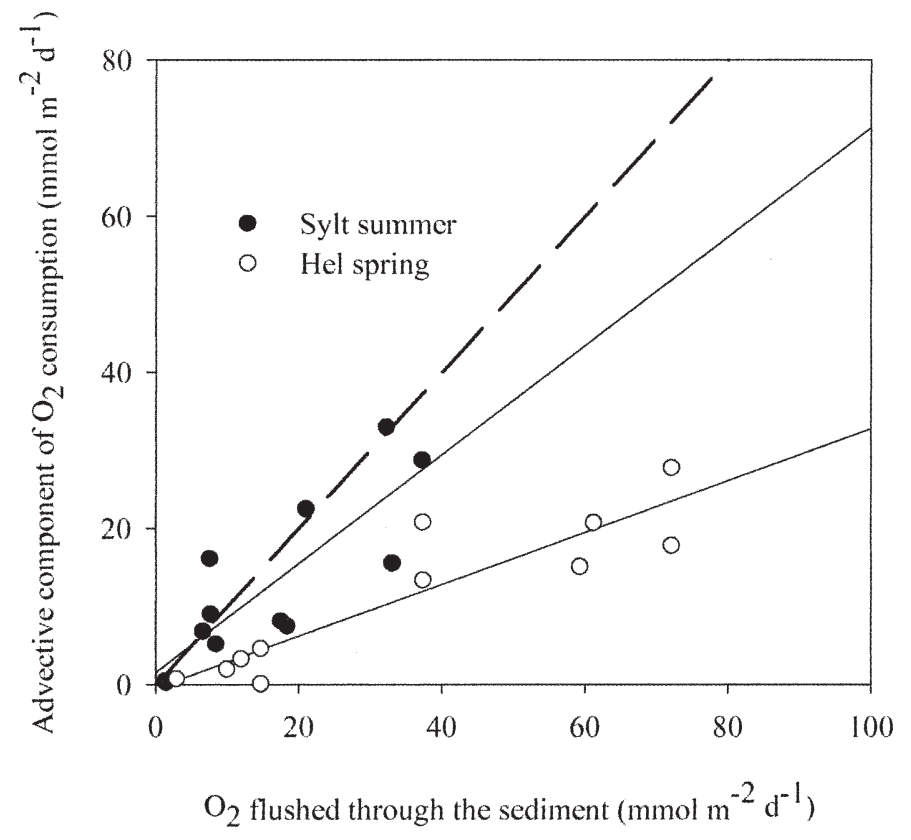

Fig. 13. A plot of the advective component of $\mathrm{O}_{2}$ consumption (defined as the $\mathrm{O}_{2}$ flux in advective chambers - the average flux in the 'diffusive' chambers) versus the rate of $\mathrm{O}_{2}$ advection through the sediments (calculated by multiplying the volume of water flushed through the sediment per day by the $\mathrm{O}_{2}$ concentration in the water column). The dashed line shows the $1: 1$ relationship, and the solid lines show the linear regression of the data from Sylt in summer and Hel in spring.

observations have previously been made upon homogenization of cohesive sediments (Hansen et al. 2000).

Table 2 summarizes the area-specific rates of sediment respiration based on the volumetric rates of $\mathrm{O}_{2}$ consumption measured in the bottle incubations integrated over the depth of $\mathrm{O}_{2}$ penetration (minimum, maximum, and average) measured in situ. Similarly, the in situ $\mathrm{TCO}_{2}$ production rates were estimated by combining the sulfate reduction rates integrated over the anoxic zone of the sediment with the oxic $\mathrm{TCO}_{2}$ production rates (bottle incubations) integrated over the oxic zone of the sediment. At both sites it can be seen that the estimated in situ benthic exchange rates of $\mathrm{O}_{2}$ and $\mathrm{TCO}_{2}$ generally fell within the range of the exchange rates measured with the chambers. At Sylt, the estimated average in situ exchange rates of $\mathrm{O}_{2}$ and $\mathrm{TCO}_{2}$ fell within the lower range of the exchange rates measured in the chambers, corresponding to sediment flushing rates of $\sim 0-5 \mathrm{~L} \mathrm{~m}^{-2} \mathrm{~d}^{-1}$. By contrast, at Hel the average estimated in situ exchange rates fell in the upper range of those measured in the chambers, corresponding to flushing rates in excess of $130 \mathrm{~L} \mathrm{~m}^{-2} \mathrm{~d}^{-1}$. This apparent difference in the sediment flushing rate at the two sites is consistent with the observed lack of topography at Sylt and, hence, of flushing, as noted at the start of the Discussion section.

Another means of estimating sediment flushing rates is to use established relationships between currents and sediment surface geometry, as was originally suggested for unidirectional flows and sand dunes by Rutherford et al. (1995). Precht and Huettel (2003) showed that the same approach could serve as a first-order estimate of sediment flushing rates under an oscillating flow regime. First, the estimated pressure perturbation over the ripples in the field was calculated using

$$
p=0.14 \rho u^{2}(\delta / 0.34 d)^{3 / 8}
$$

where $\delta$ is ripple height, $d$ is height above the surface at which the current was measured, $\rho$ is density, and $u$ is the RMS of the horizontal oscillating current velocity. Here we extract average, maximum, and minimum ripple heights of $1.75 \mathrm{~cm}, 2.52 \mathrm{~cm}$, and $1.07 \mathrm{~cm}$, respectively, from the topography data and used average, minimum, and maximum RMS oscillating current velocities of $4 \mathrm{~cm} \mathrm{~s}^{-1}, 1 \mathrm{~cm}$ $\mathrm{s}^{-1}$, and $11 \mathrm{~cm} \mathrm{~s}^{-1}$, obtained from the ADV measurements (Fig. 2c). From the pressure perturbation, the fluid exchange rate was calculated using

$$
w_{0}=\left(2 k / \rho v L_{D}\right) p
$$

where $k$ is permeability, $v$ is kinematic viscosity, and $L_{D}$ is the length scale of the ripple. The average, maximum, and minimum length scales of $11.5 \mathrm{~cm}, 15.5 \mathrm{~cm}$, and $7.3 \mathrm{~cm}$, respectively, were extracted from the topography measurements. Using these data we obtained average, maximum, and minimum pressure perturbations of $0.17 \mathrm{~Pa}, 1.5 \mathrm{~Pa}$, and $0.0088 \mathrm{~Pa}$, respectively, over the ripple, which would lead to average, maximum, and minimum sediment flushing rates of $5.9,81$, and $0.22 \mathrm{~L} \mathrm{~m}^{-2} \mathrm{~d}^{-1}$, respectively. This range is somewhat lower than the previously estimated in situ flushing rate of $\sim 130 \mathrm{~L} \mathrm{~m}^{-2} \mathrm{~d}^{-1}$ at $\mathrm{Hel}$, based on respiration measurements. For such a comparison it is, however, crucial to know the current speeds at the time the $\mathrm{O}_{2}$ microprofiles (which were used in the calculation of in situ respiration rates) were measured. Unfortunately, we have no simultaneously measured currents for the microelectrode penetration depths; however, for the planar optode penetration depths (which were similar), we do have simultaneously measured RMS current speeds of $\sim 10 \mathrm{~cm} \mathrm{~s}^{-1}$ which would result in flushing rates in the upper range of those estimated for the previous comparison.

Given uncertainties in the exact volumetric consumption rate of the sediment and the permeability at the surface as well as artefacts introduced by the measuring techniques, we consider that this provides reasonable first-order agreement with the chamber data. At this point we also note that the prevailing conditions during this field campaign were unusually calm. As such, the prevailing current speeds (the most sensitive term in Eq. 4) and sediment flushing rates in situ are most likely in the upper range of those reported here. Furthermore, flushing rates in the range of $60-130 \mathrm{~L} \mathrm{~m}^{-2} \mathrm{~d}^{-1}$ are in good agreement with other measurements and estimates of sediment flushing rates under oscillating flow. At a relatively permeable site $\left(3.7 \times 10^{-10} \mathrm{~m}^{2}\right)$ in the Mediterranean Sea, a flushing rate of $140 \mathrm{~L} \mathrm{~m}^{-2} \mathrm{~d}^{-1}$ was estimated based on direct pore-water flow measurements (Precht and Huettel 2004). It has also been estimated that oscillating flow (which dominates at Hel) may induce sediment flushing rates in excess of 50 $100 \mathrm{~L} \mathrm{~m}^{-2} \mathrm{~d}^{-1}$ (Precht and Huettel 2003). 
Toward a common approach for measuring process rates in permeable sediments - Our data here clearly show that advective pore-water exchange had a marked effect on the exchange of $\mathrm{TCO}_{2}$ and $\mathrm{O}_{2}$. Given that much attention is now focused on scaling up and incorporating benthic respiration rates for global budgets (Middelburg et al. 2005) and predictive modeling (Berg et al. 2003), we suggest that there should be a focus on obtaining a standardized approach to accurately and reliably measure benthic $\mathrm{O}_{2}$ and $\mathrm{TCO}_{2}$ exchange occurring in situ, which may be highly decoupled from the actual sediment mineralization rates. Often, benthic mineralization rates in sand sediments are inferred from $\mathrm{O}_{2}$ and $\mathrm{TCO}_{2}$ fluxes measured in smalldiameter core incubations (e.g., Therkildsen and Lomstein 1993; Rysgaard et al. 2000; Ferguson et al. 2003), which exclude advective pore-water exchange and most likely underestimate the true exchange rates. Chamber incubations, such as those used here, provide a useful insight into interactions between pore-water advection, solute fluxes, and reaction rates, insight which cannot be seen independently of the boundary layer flow, topography, and water column organic matter content present at the time of the measurement in permeable sediments. Such measurements, however, provide only the net outcome of this complicated interaction of reaction and transport, under one flow field geometry and flushing rate. Given the highly dynamic nature of permeable sediments, we suggest that a departure from the traditional approach to measuring rates in relatively stable cohesive sediment environments is needed.

We identify reaction and transport as two key factors essential to extending our understanding of permeable sediments. Fundamentally it is the interplay between organic matter mineralization rates and the transport of solutes through permeable beds that leads to a particular biogeochemical condition, as illustrated by the contrast between the dominance of oxic and anoxic mineralization pathways at Sylt and Hel. We suggest that organic matter mineralization rates be made under controlled conditions using static core incubations, as described by Jahnke et al. (2005). This approach assumes that (1) the mineralization of labile organic matter will not be affected greatly by the absence of $\mathrm{O}_{2}$, which seems reasonable based on our current understanding of organic matter breakdown (Kristensen et al. 1995; Hulthe et al. 1998) and that (2) there will not be a significant depletion in the organic matter pool over short incubation timescales, which also seems reasonable given the observed linear trends in solute concentrations observed by Jahnke et al. (2005).

Transport in permeable sediments is still very poorly constrained in the field, and there are significant technological challenges to accurately measuring transport in situ, as evidenced by the limited number of publications in this area (Webb and Theodor 1972; Precht and Huettel 2004; Reimers et al. 2004). The limited data available do, however, clearly show that flow fields around sediment topography conform well to those expected from ex situ experiments (Huettel and Gust 1992; Huettel and Webster 2001; Precht et al. 2004) and model simulations (Shum 1992). We suggest that there is a need for a concerted effort to create two-dimensional models of pore-water flow fields based on sediment topography and currents measured in situ. The accuracy of these models can then be assessed by spot measurements of pore-water flows under ripples, or possibly using the two-dimensional observations of $\mathrm{O}_{2}$ in situ, such as those observed at Hel. Following the approach of Cook et al. (2006), diagenetic models can then be overlayed on the flow model so that the net biogeochemical outcome can be simulated and the effect of changing conditions (topography, bottom currents) evaluated. The validity of these models can then be assessed by comparison with in situ solute distributions or chamber incubations.

In summary, our measurements demonstrate that advective pore-water exchange had a marked effect on the relative and absolute fluxes of $\mathrm{O}_{2}$ and $\mathrm{TCO}_{2}$ across the sediment-water interface in sublittoral permeable sediments. This was observed in chambers as well as in situ using microelectrodes and planar optodes. Furthermore, organic matter degradation pathways in sand can be highly variable, ranging from predominantly aerobic to predominantly sulfate reduction, depending on temperature, availability of degradable organic matter in the sediment, sediment permeability, sediment topography, and boundary layer flow velocity. These variables change on different timescales that range from months (permeability) to weeks (organic matter content) to days (temperature) to hours (topography) to minutes (boundary flow). Fluctuations in flushing intensity alter sedimentary biogeochemical settings (e.g., oxygen, nitrate, and sulfide content) within minutes (e.g., oxygen injection), with consequences for microbial decomposition that are poorly understood. Episodic events such as major storms can profoundly shift the sedimentary biogeochemical processes, for periods of weeks to months, to another pathway (e.g., anoxic to oxic) by reoxidizing reduced substances, enhancing permeability, advective oxygen penetration, and removal of organic matter. To date, most studies of metabolism in shallow permeable sediments have ignored advective pore-water flow and its temporal variability and have, therefore, most likely underestimated the true metabolic rates. Thus, understanding the role of permeable sediments in the coastal cycles of matter requires new approaches and sampling schemes that take the tight coupling between the interfacial fluxes and variable boundary layer flows into account.

\section{References}

Anderson, L. G., P. O. Hall, A. Iverfeldt, M. M. R. Van Der Loeff, B. Sundby, and S. F. G. Westerlund. 1986. Benthic respiration measured by total carbonate production. Limnol. Oceanogr. 31: 319-329.

Behrens, J. W., H. J. Stahl, J. F. Steffensen, and R. N. Glud. 2007. Oxygen dynamics around buried lesser sandeels Ammodytes tobianus (Linnaeus 1785): mode of ventilation and oxygen requirements. J. Exp. Biol. 210: 1006-1014.

Berg, P., S. Rysgandd, And B. Thamdrup. 2003. Dynamic modeling of early diagenesis and nutrient cycling. A case study in an Arctic marine sediment. Am. J. Sci. 303: 905-955.

BoudreAu, B. P., AND others. 2001. Permeable marine sediments: Overturning an old paradigm. EOS Transcripts Am. Geophys. Union 82: 133-136. 
CAi, W.-J., And F. SAyles. 1996. Oxygen penetration depths and fluxes in marine sediments. Mar. Chem. 52: 123-131.

Canfield, D. E., B. Thamdrup, and E. Kristensen. 2005. Aquatic geomicrobiology. Elsevier.

CoOK, P. L. M., AND others. 2006. Quantification of denitrification in permeable sediments: Insights from a two dimensional simulation analysis and experimental data. Limnol. Oceanogr. Methods 4: 294-307.

De BeER, D., AND others. 2005. Transport and mineralization rates in North Sea sandy intertidal sediments, Sylt-Romo Basin, Wadden Sea. Limnol. Oceanogr. 50: 113-127.

EMERY, K. O. 1968. Relict sediments on continental shelves of the world. Am. Assoc. Petroleum Geol. Bull. 52: 445464.

Ferguson, A. J. P., B. D. Eyre, and J. M. Gay. 2003. Organic matter and benthic metabolism in euphotic sediments along shallow sub-tropical estuaries, northern New South Wales, Australia. Aquat. Microb. Ecol. 33: 137-154.

Froelich, P. N., AND others. 1979. Early oxidation of organicmatter in pelagic sediments of the Eastern Equatorial Atlantic-suboxic diagenesis. Geochim. Cosmochim. Acta 43: $1075-1090$.

Glud, R. N., J. K. Gundersen, and N. B. Ramsing. 2000. Electrochemical and optical oxygen microsensors for in situ measurements, p. 19-72. In J. Buffle and G. Horvai [eds.], In situ monitoring of aquatic systems: Chemical analysis and speciation. Wiley.

- , N. P. Revsbech, B. B. Jørgensen, And M. HutTel. 1995. Calibration and performance of the stirred flux chamber from the benthic Lander Elinor. Deep-Sea Res. I Oceanogr. Res. Pap. 42: 1029-1042.

- - H. Røy, And B. B. Jørgensen. 2003. Seasonal dynamics of benthic $\mathrm{O}_{2}$ uptake in a semienclosed bay: Importance of diffusion and faunal activity. Limnol. Oceanogr. 48: 1265-1276.

, N. B. Ramsing, J. K. Gundersen, and I. Klimant. 1996. Planar optrodes: A new tool for fine scale measurements of two-dimensional $\mathrm{O}_{2}$ distribution in benthic communities. Mar. Ecol. Prog. Ser. 140: 217-226.

- A. Tengberg, M. Kuhl, P. O. J. Hall, I. Klimant, and G. Host. 2001. An in situ instrument for planar $\mathrm{O}_{2}$ optode measurements at benthic interfaces. Limnol. Oceanogr. 46: 2073-2080.

—, F. Wenzhöfer, A. Tengberg, M. Middelboe, K. Oguri, And H. Kitazato. 2005. Distribution of oxygen in surface sediments from central Sagami Bay, Japan: In situ measurements by microelectrodes and planar optodes. Deep-Sea Res. I Oceanogr. Res. Pap. 52: 1974-1987.

GrasshofF, K. 1983. Methods of seawater analysis, 2nd ed. Verlag Chemie.

Green, M. A., And R. C. Aller. 2001. Early diagenesis of calcium carbonate in Long Island Sound sediments: Benthic fluxes of $\mathrm{Ca} 2+$ and minor elements during seasonal periods of net dissolution. J. Mar. Res. 59: 769-794.

Gribsholt, B., J. E. Kostka, and E. Kristensen. 2003. Impact of fiddler crabs and plant roots on sediment biogeochemistry in a Georgia saltmarsh. Mar. Ecol. Prog. Ser. 259: $237-251$.

Gundersen, J. K., And B. B. Jørgensen. 1990. Microstructure of diffusive boundary-layers and the oxygen-uptake of the seafloor. Nature 345: 604-607.

Hansen, J. B., B. Thamdrup, and B. B. Jørgensen. 2000. Anoxic incubation of sediment in gas-tight plastic bags: A method for biogeochemical process studies. Mar. Ecol. Prog. Ser. 208: 273-282.
Hargrave, B. T., and G. A. Phillips. 1981. Annual in situ carbon dioxide and oxygen flux across a subtidal marine sediment. Estuar. Coast. Shelf Sci. 12: 725-737.

Hedtkamp, S. 2005. Shallow subtidal sand: Permeability, nutrient dynamics microphytobenthos and organic matter. Ph.D. thesis, Christian Albrechts Univ.

Heip, C. H. R., N. K. Goosen, P. M. J. Herman, J. Kromkamp, J. J. Middelburg, and K. Soetaert. 1995. Production and consumption of biological particles in temperate tidal estuaries. Oceanogr. Mar. Biol. Annu. Rev. 33: 1-149.

Hopkinson, C. S., A. E. Giblin, J. Tucker, and R. H. Garritt. 1999. Benthic metabolism and nutrient cycling along an estuarine salinity gradient. Estuaries 22: 863-881.

Huettel, M., AND G. Gust. 1992. Solute release mechanisms from confined sediment cores in stirred benthic chambers and flume flows. Mar. Ecol. Prog. Ser. 82: 187-197.

—, AND I. T. Webster. 2001. Porewater flow in permeable sediments, p. 144-179. In B. P. Boudreau and B. B. Jørgensen [eds.], The benthic boundary layer. Oxford Univ. Press.

Hulthe, G., S. Hulth, and P. O. J. Hall. 1998. Effect of oxygen on degradation rate of refractory and labile organic matter in continental margin sediments. Geochim. Cosmochim. Acta 62: 1319-1328.

Jahnke, R. A., J. R. Nelson, R. L. Marinelli, and J. E. Eckman. 2000. Benthic flux of biogenic elements on the Southeastern US continental shelf: Influence of pore water advective transport and benthic microalgae. Cont. Shelf Res. 20: 109-127.

- M. Richards, J. Nelson, C. Robertson, A. Rao, and D. B. JAHNKE. 2005. Organic matter mineralization and porewater exchange rates in permeable South Atlantic Bight continental shelf sediments. Cont. Shelf Res. 25: 1433-1452.

Janssen, F., P. Faerber, M. Huettel, V. Meyer, and U. Witte. 2005a. Pore-water advection and solute fluxes in permeable marine sediments (I): Calibration and performance of the novel benthic chamber system sandy. Limnol. Oceanogr. 50: 768-778.

, M. Huettel, And U. Witte. 2005b. Pore-water advection and solute fluxes in permeable marine sediments (II): Benthic respiration at three sandy sites with different permeabilities. Limnol. Oceanogr. 50: 779-792.

Jensen, M. M., B. Thamdrup, S. Rysgaard, M. Holmer, And H. Fossing. 2003. Rates and regulation of microbial iron reduction in sediments of the Baltic-North Sea transition. Biogeochemistry 65: 295-317.

Jeroschewski, P., C. Steuckart, and M. Kuhl. 1996. An amperometric microsensor for the determination of $\mathrm{H} 2 \mathrm{~S}$ in aquatic environments. Anal. Chem. 68: 4351-4357.

Jørgensen, B. B. 1978. Comparison of methods for the quantification of bacterial sulfate reduction in coastal marine-sediments. 1. Measurement with radiotracer techniques. Geomicrobiol. J. 1: 11-27.

Kallmeyer, J., T. G. Ferdelman, A. Weber, H. Fossing, and B. B. JøRGENSEN. 2004. A cold chromium distillation procedure for radiolabelled sulfide applied to sulfate reduction measurements. Limnol. Oceanogr. Methods 2: 171-180.

Khalili, A., A. J. Basu, and M. Huettel. 1997. A non-Darcy model for recirculating flow through a fluid-sediment interface in a cylindrical container. Acta Mech. 123: 75-87.

Kostka, J. E., and G. W. Luther. 1994. Partitioning and speciation of solid-phase iron in salt-marsh sediments. Geochim. Cosmochim. Acta 58: 1701-1710.

, B. Thamdrup, R. N. Glud, and D. E. Canfield. 1999. Rates and pathways of carbon oxidation in permanently cold Arctic sediments. Mar. Ecol. Prog. Ser. 180: 7-21. 
KRISTENSEN, E. 1993. Seasonal variations in benthic community metabolism and nitrogen dynamics in a shallow, organic-poor Danish lagoon. Estuar. Coast. Shelf Sci. 36: 565-586.

, S. I. Ahmed, and A. H. Devol. 1995. Aerobic and anaerobic decomposition of organic matter in marine sediment: Which is fastest? Limnol. Oceanogr. 40: 1430-1437.

Li, M. Z., AND C. L. Amos. 1998. Predicting ripple geometry and bed roughness under combined waves and currents in a continental shelf environment. Cont. Shelf Res. 18: 941-970.

Lohse, L., E. H. G. Epping, W. Helder, and W. Van RaAphorst. 1996. Oxygen porewater profiles in continental shelf sediments of the North Sea: Turbulent versus molecular diffusion. Mar. Ecol. Prog. Ser. 145: 63-75.

Mackin, J. E., and K. T. Swider. 1989. Organic-matter decomposition pathways and oxygen-consumption in coastal marine-sediments. J. Mar. Res. 47: 681-716.

Meysman, F. J. R., O. S. Galaktionov, and J. J. Middelburg. 2005. Irrigation patterns induced in permeable sediments by burrow ventilation: A case study of Arenicola marina. Mar. Ecol. Prog. Ser. 303: 195-212.

Middelburg, J. J., C. M. Duarte, and J. P. Gattuso. 2005. Respiration in coastal benthic communities, p. 206-224. In P. A. del Giorgio and P. J. Williams [eds.], Respiration in aquatic ecosystems. Oxford Univ. Press.

Precht, E., U. Franke, L. Polerecky, and M. Huettel. 2004. Oxygen dynamics in permeable sediments with wave-driven porewater exchange. Limnol. Oceanogr. 49: 693-705.

$\longrightarrow$, AND M. HuetTel. 2003. Advective pore-water exchange driven by surface gravity waves and its ecological implications. Limnol. Oceanogr. 48: 1674-1684.

- AND —. 2004. Rapid wave driven porewater exchange in a permeable coastal sediment. J. Sea Res. 51: 93-107.

ReIMERs, C. E., AND OTHERs. 2004. In situ measurements of advective solute transport in permeable shelf sands. Cont. Shelf Res. 24: 183-201.

Revsbech, N. P. 1989. An oxygen microsensor with a guard cathode. Limnol. Oceanogr. 34: 474-478.

Røy, H., M. Huettel, And B. B. Jørgensen. 2005. The influence of topography on the functional exchange surface of marine soft sediments, assessed from sediment topography measured in situ. Limnol. Oceanogr. 50: 106-112.

Roychoudhury, A. N., P. Van Cappellan, J. E. Kostka, and E. VIOLLIER. 2003. Kinetics of microbially mediated reactions: Dissimilatory sulfate reduction in saltmarsh sediments (Sapelo Island, Georgia, USA). Estuar. Coast. Shelf Sci. 56: 1001-1010.
Rutherford, J. C., J. D. Boyle, A. H. Elliott, T. V. J. Hatherell, And T. W. Chiu. 1995. Modeling benthic oxygen-uptake by pumping. J. Environ. Eng. Asce 121: 84 95.

Rysgaard, S., P. B. Christensen, M. V. Sorensen, P. Funch, and P. BERG. 2000. Marine meiofauna, carbon and nitrogen mineralization in sandy and soft sediments of Disko Bay, West Greenland. Aquat. Microb. Ecol. 21: 59-71.

Shum, K. T. 1992. Wave-induced advective transport below a rippled water-sediment interface. J. Geophys. Res. Oceans 97: 789-808.

Slomp, C. P., J. F. P. Malschaert, L. Lohse, and W. VANRAAPHORST. 1997. Iron and manganese cycling in different sedimentary environments on the North Sea continental margin. Cont. Shelf Res. 17: 1083-1117.

Thamdrup, B. 2000. Bacterial manganese and iron reduction in aquatic sediments, p. 41-84. Advances in microbial ecology. V. 16. Kluwer Academic/Plenum Publishers.

Therkildsen, M. S., AND B. A. Lomstein. 1993. Seasonalvariation in net benthic C-mineralization in a shallow estuary. FEMS Microbiol. Ecol. 12: 131-142.

Webb, J. E., And J. Theodor. 1968. Irrigation of submerged marine sands through wave action. Nature 220: 682 683.

- AND 1 1972. Wave-induced circulation in submerged sands. J. Mar. Biol. Assoc. U K 52: 903-914.

Wenzhöfer, F., AND R. N. Glud. 2004. Small-scale spatial and temporal variability in coastal benthic $\mathrm{O}_{2}$ dynamics: Effects of faunal activity. Limnol. Oceanogr. 49: 1471-1481.

, O. Holby, R. N. Glud, H. K. Nielsen, and J. K. GUNDERSEN. 2000. In situ microsensor studies of a shallow water hydrothermal vent at Milos, Greece. Mar. Chem. 69: 43-54.

Werner, U., AND others. 2006. Spatial patterns of aerobic and anaerobic mineralization rates and oxygen penetration dynamics in coral reef sediments. Mar. Ecol. Prog. Ser. 309: 93-105.

Wheatcroft, R. A. 1994. Temporal variation in bed configuration and one-dimensional bottom roughness at the mid shelf STRESS site. Cont. Shelf Res. 14: 1167-1190.

Received: 14 June 2006

Accepted: 13 February 2007 Amended: 15 March 2007 